Article

\title{
Implementation of Different MPPT Techniques in Solar PV Tree under Partial Shading Conditions
}

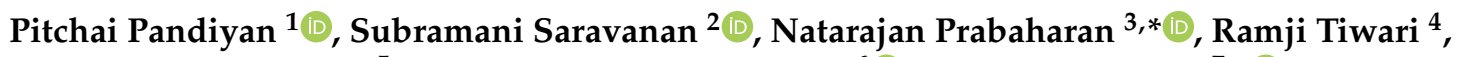 \\ Thangam Chinnadurai ${ }^{5}$, Neelakandan Ramesh Babu ${ }^{6}(\mathbb{D}$ and Eklas Hossain $7, * \mathbb{C}$ \\ 1 Department of EEE, KPR Institute of Engineering and Technology, Coimbatore 641407, India; \\ pandyyan@gmail.com \\ 2 Department of EEE, Sri Krishna College of Technology, Coimbatore 641042, India; saravanans087@gmail.com \\ 3 Department of EEE, SASTRA Deemed University, Thanjavur 613401, India \\ 4 Department of EEE, Sri Krishna College of Engineering and Technology, Coimbatore 641008, India; \\ tiwariramjis@gmail.com \\ 5 Department of ICE, Sri Krishna College of Technology, Coimbatore 641042, India; jeevadurai07@gmail.com \\ 6 Department of EEE, M.Kumarasamy College of Engineering, Karur 639113, India; nrameshme@gmail.com \\ 7 Department of Electrical Engineering \& Renewable Energy, Oregon Institute of Technology, \\ Klamath Falls, OR 97601, USA \\ * Correspondence: prabaharan.nataraj@gmail.com (N.P.); eklas.hossain@oit.edu (E.H.)
}

check for updates

Citation: Pandiyan, P.; Saravanan, S.; Prabaharan, N.; Tiwari, R.;

Chinnadurai, T.; Babu, N.R.; Hossain, E. Implementation of Different MPPT Techniques in Solar PV Tree under Partial Shading Conditions. Sustainability 2021, 13, 7208 . https://doi.org/10.3390/su13137208

Academic Editors: Tomonobu Senjyu and Alessandro Franco

Received: 7 April 2021

Accepted: 31 May 2021

Published: 28 June 2021

Publisher's Note: MDPI stays neutral with regard to jurisdictional claims in published maps and institutional affiliations.

Copyright: (c) 2021 by the authors. Licensee MDPI, Basel, Switzerland. This article is an open access article distributed under the terms and conditions of the Creative Commons Attribution (CC BY) license (https:// creativecommons.org/licenses/by/ $4.0 /)$.

\begin{abstract}
This paper presents the design and analytical modeling of the proposed solar photovoltaic standalone system under varying environmental conditions. The proposed system consists of a unique structure of a solar PV-tree, maximum power point tracking (MPPT) technique, and DC-DC converter. The output voltage acquired from the solar PV tree is low. A DC-DC boost converter is utilized to step-up the required amount of voltage level. In this paper, the appropriate duty cycle is obtained for extracting the optimum power from the solar PV tree by using various MPPT mechanisms such as perturb and observe (P\&O), incremental conductance (INC), and a radial basis function network (RBFN)-based neural network (NN). The proposed solar photovoltaic tree-based energy harvesting system is designed and validated by using MATLAB/SIMULINK software and real-time application. The simulation results of the above-mentioned three techniques are compared with each other in order to show the effectiveness of the proposed system with RBFN. The RBFNMPPT provides a significant improvement in tracking efficiency of $6.0 \%$ and $5.72 \%$ as compared with the P\&O method and the INC method at $1000 \mathrm{~W} / \mathrm{m}^{2}$ irradiance condition. From the simulation and real-time results, it is concluded that the RBFN-based NN provides better tracking efficiency and less oscillation as compared with the other two algorithms.
\end{abstract}

Keywords: solar PV tree; boost converter; radial basis function network (RBFN); incremental conductance (INC); perturb and observe (P\&O); maximum power point tracking (MPPT)

\section{Introduction}

Energy is important for the world to provide better living standards and also support every part of other essential elements of society. The problems faced by the conventional energy sources are increases in the cost of fossil fuels, environmental factors, and their effects on human health. Researchers are looking forward to generating pollution-free electricity by means of sustainable energy sources. Sustainable energy sources are naturally available forms such as wind, biomass, solar, fuel cells, and water that have been deemed clean and inexhaustible. Solar energy is predominantly utilized for producing electrical energy among the other sustainable energy sources because of its lower maintenance and minimum operational cost. Development of solar energy harvesting has been gaining more attention recently, and is predominately utilized for stand-alone and grid-connected systems [1]. Most of the existing solar power generation utilizes the flat solar panel configuration or solar farms. The flat solar PV panel-based energy harvesting systems 
occupy an enormous quantity of functional space. However, the solar PV tree-based energy harvesting system utilizes only a part of that land space for the equal quantity of energy production. The solar PV tree is an arrangement of solar panels in a tree configuration, which is more advantageous as compared with the flat panel configuration. Solar PV tree-based energy generation is one of the means of electrical energy production in the metropolitan region to save land space and meet the required energy demand of the people. The solar PV tree model is the most viable solution that may be implemented to fulfill the electricity demand exclusively for the power-off period. Additionally, if it produces the excess energy, it may give the power to the grid. A detailed summary of solar tree structure is explained in [2].

In [3], the solar PV tree design's branches have a single PV cell, and it follows the Fibonacci series pattern. In [4], the semi-dome design was designed to extract the solar energy using the solar PV tree model with tilt angle varying from $0-46^{\circ}$. In [5], the treestructured hybrid energy generator utilizing piezoelectric and photovoltaic effects at a nanometer size was demonstrated. In [6], the two solar PV tree structures based on 3/8 and 2/5 phyllotaxy pattern were discussed, and the results were found to be better as compared with the conventional flat panel arrangement.

The currently available PV module in the market gives a low conversion efficiency of approximately $20 \%$, and its characteristics are affected by its non-linear behavior and the external parameter variation. Owing to the lower conversion efficiency compared with other alternate energy sources, the voltage produced in the PV module is low, and it can be higher with the combination of series PV module. However, it is not possible to operate at the maximum point of the converter under the varying load condition. The generation of power from the PV module changes according to the insolation, module temperature variation, dust, shade, and spectrum from sun. The partial shading condition is one of the most challenging conditions that influence the efficiency of the PV module because of its installation in an open-air environment. To overcome this issue, the MPPT technique is implemented to extract and maintain the maximum power at the output of the solar PV module array, which is the most feasible solution.

Several methods pertaining to MPPT algorithms have been developed to track the optimal point from the PV array under partial shading conditions. Some of the conventional methods are perturb and observe (P\&O) [7], hill climbing (HC), incremental conductance (INC) [8], neural network (NN) algorithms [9], soft computing techniques, fuzzy logic controller (FLC) [10], evaluation-based techniques (differential evolution (DE) [11], simulated annealing (SA) [12], particle swarm optimization (PSO) [13], the genetic algorithm (GA) [14], cuckoo search (CS) [15], and artificial bee colony (ABC) [16]. Among these techniques, the three different algorithms, namely P\&O, INC, and NN, are chosen for implementation in the proposed system.

The P\&O technique is the classical MPPT algorithm, which is generally used due to its control simplicity. It is very simple and easy to realize and produces better performance in standard test conditions. For the P\&O algorithm developed in [17], the rate of change of PV array output used as input to the proportional-integral controller to produce the different perturb values according to the input change.

The incremental conductance (INC) method with direct control was implemented in [18]; the selection of suitable iteration step size provides the optimal point quickly. In this technique, the solar PV output is regulated depending upon the maximum power point position, which depends upon the instantaneous and incremental conductance of the PV array.

The soft-computing-based MPPT algorithms such as FLC and NN compute the optimal point with greater accuracy and generates a rapid response when compared to the conventional method. RBFN is one of the NN techniques that has the potential to control the time-varying condition and non-linear effects effectively along with the fastest convergence and easiest network configuration $[19,20]$. 
The operating voltage for the maximum power point based on solar PV modules is very low. Due to lower voltage, it is not possible to connect the load directly. By using a conventional boost converter, the low voltage is stepped up based on the load requirement. The switching voltage for the boost converter is normally high for the period of conversion time.

In Figure 1, the general block diagram of the proposed work is illustrated. The current (I) and voltage (V) obtained from the solar PV tree are given to the MPPT algorithms for tracing the optimal point, and they produce the appropriate duty-cycle for the DCDC boost converter. This paper proposes a unique solar PV tree structure in which the panels are located at the different angle. The conventional boost converter is utilized in this work. The performance of the proposed system is evaluated with the three different conventional MPPT methods of P\&O, INC, and the RBFN-NN to obtain the optimum power from the individual module of the solar PV tree. A few attempts have been made in the solar tree concept, but none of them have tried to implement the MPPT techniques so far. Therefore, authors have made an attempt to implement the three different conventional MPPT algorithms with the proposed solar tree structure in this article. The proposed system (solar PV-tree concept) is examined with the constant irradiance and varying irradiance conditions. The three different algorithm values are compared with each other to corroborate that the proposed solar PV tree with RBFN-NN provides the best solution in all the climatic conditions. The different MPPT techniques have been reported in [21-23]. The proposed configuration of the solar tree structure with the RBFN MPPT technique provides enhanced output power during the partial shading condition. This MPPT strategy requires less time to reach the maximum peak point, which increases its efficiency and makes it highly robust in the non-linear application.

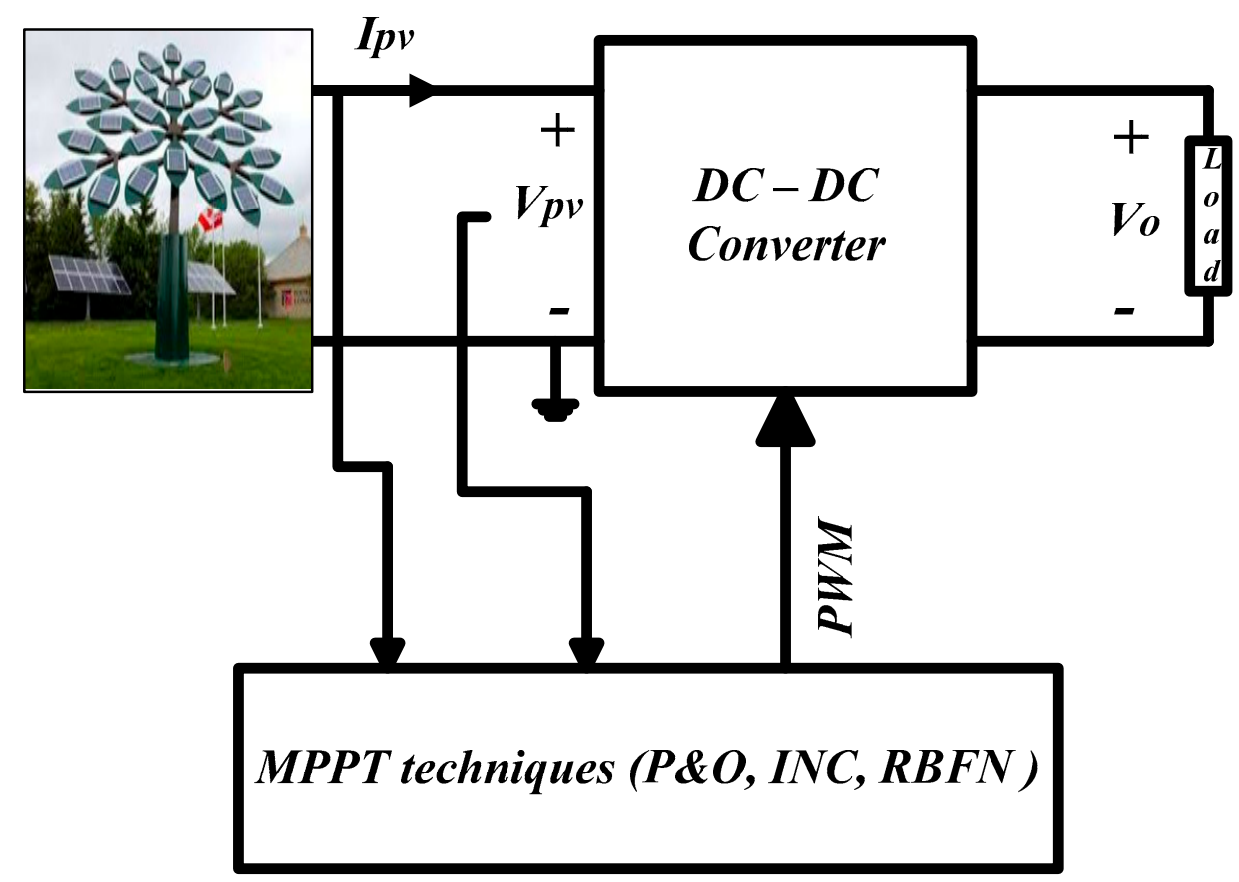

Figure 1. Block diagram of solar PV tree-based system.

The organization of this paper is as follows: Section 2 deals with the structure of the solar PV tree design. In Section 3, the modeling of the PV system is described with the help of a single diode model. Section 4 discusses the various techniques of MPPT algorithms, namely P\&O, INC, and RBF, to track the optimum power. The design of the DC-DC converter, especially the boost converter, is discussed in Section 5. Section 6 presents a complete analytical performance assessment of the different MPPT algorithms under dynamic partial shading conditions. Finally, Section 7 concludes the proposed work. 


\section{Design of Solar PV Tree}

This section may be divided by subheadings. It should provide a concise and precise description of the experimental results, their interpretation, as well as the experimental conclusions that can be drawn.

\subsection{Structure of Solar PV Tree}

The solar PV module structure is utilized to capture the radiation coming from the sun and convert it into electricity during the day time. The conventional PV module structure was designed as flat-based system either in series or parallel connection to generate the required power level where it occupies the larger amount of area. For implementing the one $\mathrm{kW}$ solar panel, the land requirement is nearly 10 square feet (maximum). The same rating can also be installed in roof tops, but it requires at least 6 square feet (minimum). In this paper, the solar PV tree system is proposed to harvest the maximum energy from the sun at the different directions where it occupies $1 / 3$ of the required area as compared with the conventional system. The proposed solar PV tree structure is shown in Figure 2. It consists of six solar PV modules, which are arranged in a layer-wise structure. The first layer is located at the top of the tree, where it has only one solar PV module. The second layer consists of two solar PV modules, which is located at the bottom of the first layer, and the arrangement of the PV module is shown in Figure 2. The subsequent layer consists of three modules, which is located at the bottom of the second layer.

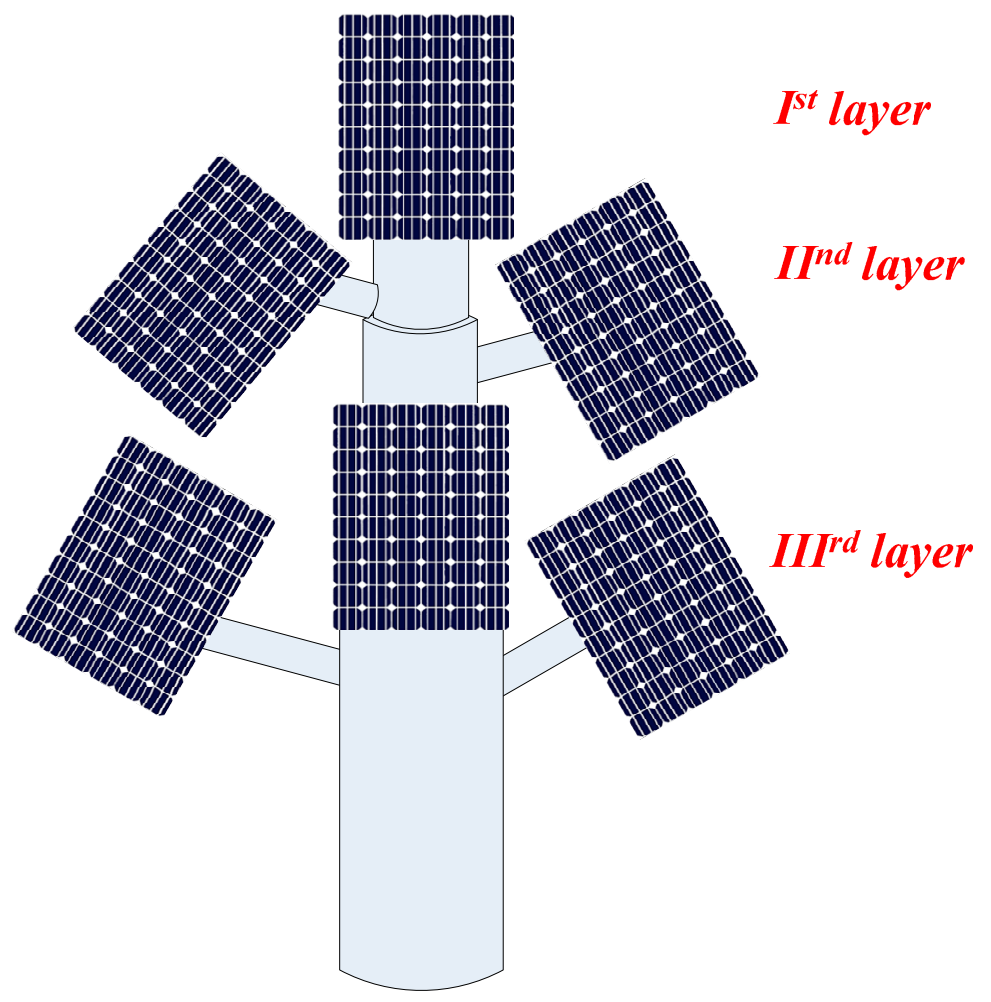

Figure 2. Proposed solar PV tree.

The total number of modules $(P)$ and layer numbers $(N)$ are denoted in Equation (1),

$$
P=\frac{N(N+1)}{2}: N=1,2,3, \ldots \ldots \infty
$$

The sun elevation angle varies around $46^{\circ}$ during the year. In this proposed work, the solar modules are arranged with a tilt angle of the same $46^{\circ}$. The hour angle changes by $15^{\circ} / \mathrm{h}$. The tilt angle is changed based on the hour angle variation along with east-west facing direction in order to capture the maximum sunlight at the specific location in the 
daytime. The center solar module in the proposed system is facing south and is also located at the latitude angle, whereas the rest of the solar modules are arranged in such a way that they form in a semi-dome fashion like the structure around this central one [4]. The layers' numbers start from the top and end at the bottom, and the numbers for solar modules in the specific layer start on the left and end on the right. If more than one middle-layer-based solar energy harvesting tree exists, the layer with a greater number of solar modules is considered the middle layer, and those middle-layered solar modules are directed at the latitude angles of $+23^{\circ}$ and $-23^{\circ}$. The rest of the layered solar modules are directed in and around the angles of $46^{\circ},+23^{\circ}$, and $-23^{\circ}$. The proposed 3-layered solar energy harvesting tree is depicted in Figure 3, which is oriented around these three mentioned fixed tilt angles. The intermediate tilt angles of the solar tree are estimated through the Equation (2)

$$
T_{a}= \pm \frac{23^{\circ}}{N_{C E}+1}
$$

where $N_{C E}$-number of layers available in between the center and end layer; $T_{a}$-intermediate tilt angle. The rules for selecting the tilt angles are as follows.

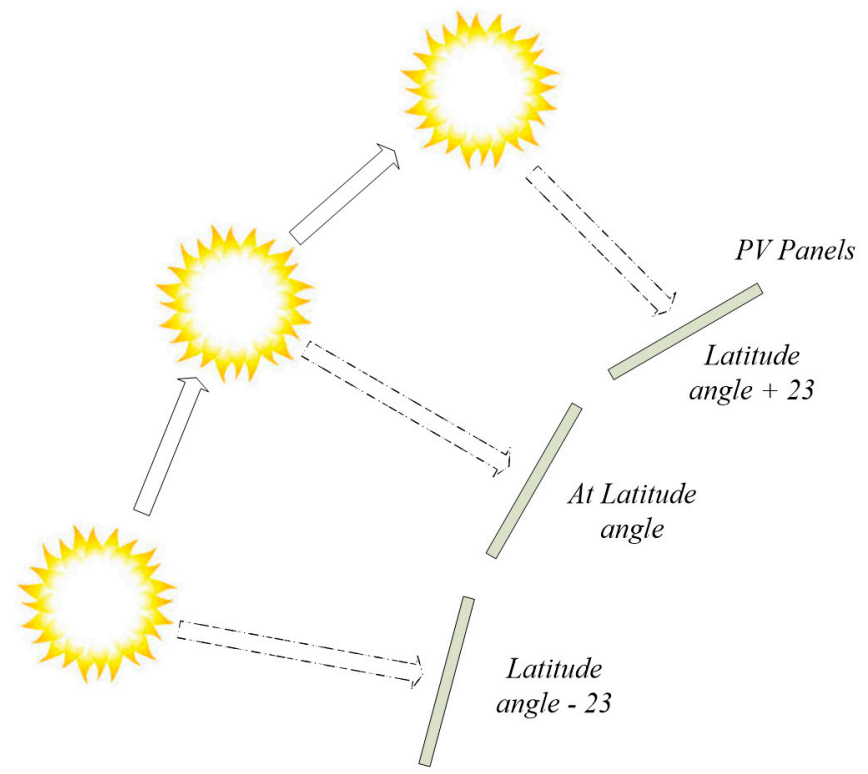

(a)

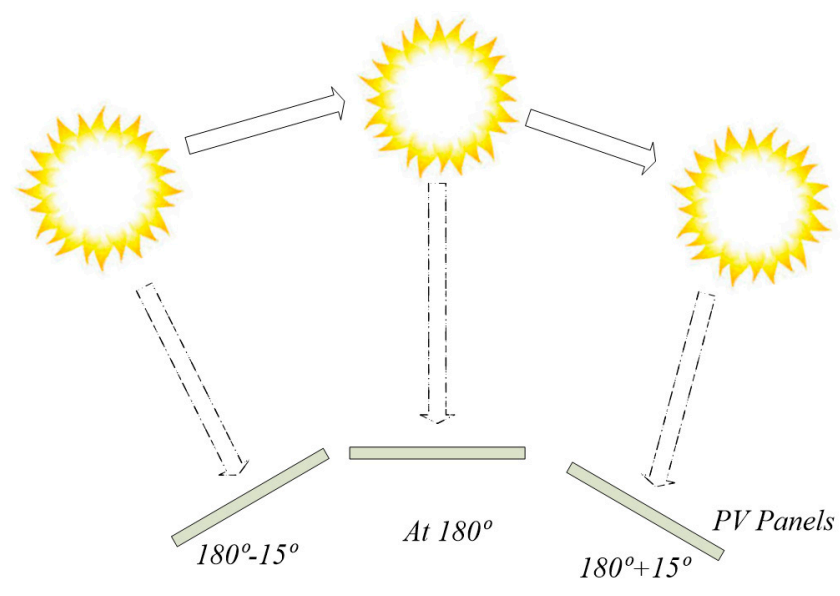

(b)

Figure 3. Tilt and orientation angles in solar energy harvesting PV tree. (a) Tilt angles of PV panels; (b) Orientation angles of PV panels. 
Only fixed tilt angles are used for the number of layers available in between the center layer and end layer. The tilt angle is positive for the layers arranged above the center layer, whereas the tilt angle is negative for the layers below the center layer.

The solar modules are situated in the center of each layer are directed toward the geographical south in the northern hemisphere, while the remaining solar modules are directed by the separation angle of $15^{\circ}$ from each other. The hour angle-based angular speed $\left(A_{s}\right)$ is determined using Equation (3).

$$
A_{s}=15^{\circ} \times\left(N M_{x}-1\right)
$$

The central solar module tilt angle of each layer is geographically south, i.e., $180^{\circ}$, and the direction angles of the remaining solar modules are found by adding or subtracting $15^{\circ}$ and $180^{\circ}$ (orientation angle of central solar module).

\subsection{Rating of Solar Module}

The power rating of each solar module in a solar PV tree can be categorized in two different ways. In the first technique, the same wattage rating is chosen for all modules. The different wattage ratings are selected for each module in the second technique. The second technique seems to be good, and the higher wattage rating solar modules are placed exactly to capture the sunshine directly, whereas the lower wattage rating solar modules are arranged in a manner to trap the sunlight in off-peak sunlight timings [4]. In the solar tree, the first two layers should have a higher wattage rating than the lower layers. The drawbacks of the second technique are that the inverter produces more losses and is not applicable to the large-scale grid-connected power system. Hence, in this work, the first technique was adopted.

\section{Mathematical Modeling of Solar PV Cell}

The PV cells are manufactured using semiconductor materials with necessary doping in the $\mathrm{p}-\mathrm{n}$ junction, which are used to allow the current flow once external potential is applied (e.g., temperature and irradiance) [24]. For obtaining the higher output voltage value, the solar PV cells are interconnected in series configuration. To produce the required larger current, the solar PV modules are interconnected in a parallel manner. In order to estimate the P-V and I-V characteristic curves of the solar PV cells, a single diode model is employed, owing to its simplicity and accuracy. Figure 4 illustrates the corresponding electrical equivalent model of the single PV cell modeled, which consists of the combination of a diode, a series resistance, shunt resistances, and a current source. The output DC current equation of the equivalent single-diode circuit is represented in Equation (4).

Practical Model

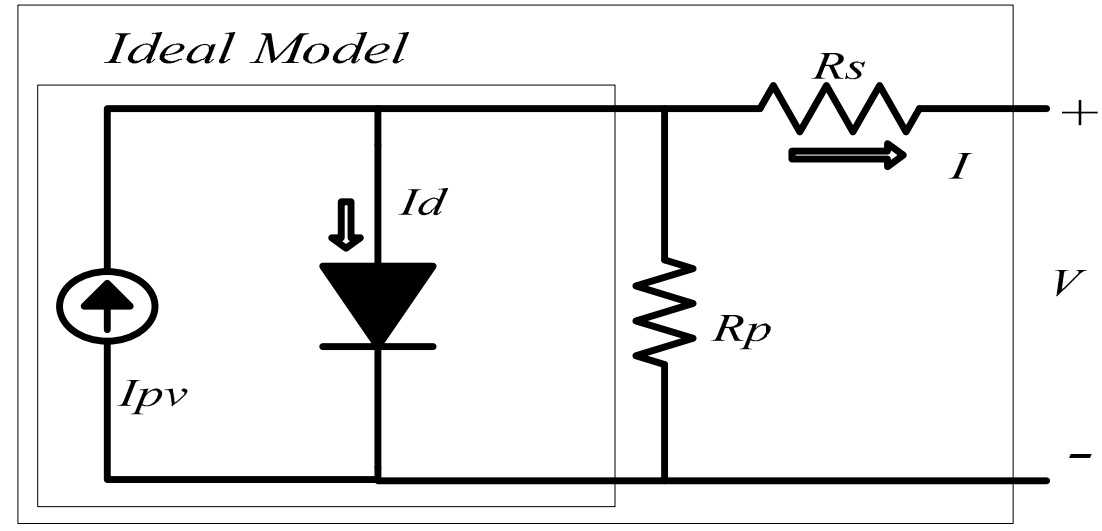

Figure 4. PV cell equivalent circuit. 
Equation (4) expresses the output current $(I)$, which consists of the electrical parameters and voltage output $(V)$ of the solar PV cell,

$$
I=I_{p v}-I_{s}\left(\exp \left[\frac{q\left(V+R_{s e} I\right)}{N_{s} k T a}\right]-1\right)-\frac{V+R_{s e} I}{R_{s h}}
$$

where $I$ is current output, $V$ is voltage output of the solar PV cell, $I_{p v}$ is output of photogenerated current and it depends on the temperature related in Equation (5), Is represents the reverse saturation current of the single diode equivalent model, $q$ is the charge of an electron $\left(1.6021 \times 10^{-19}{ }^{\circ} \mathrm{C}\right), R_{s h}$ and $R_{s e}$ are the shunt and series resistances of solar PV cell, respectively, $k$ is the Boltzmann constant $\left(1.3806 \times 10^{-23} \mathrm{~J} / \mathrm{K}\right), N_{s}$ is the number of cells connected in series, $a$ is the ideality factor of diode equivalent model, and $T$ is the absolute operating condition temperature of the solar PV array.

$$
\begin{gathered}
I_{p v}=\left(I_{p v, n}+K_{I} \Delta T\right) \frac{G}{G_{n}} \\
\Delta T=T-T_{n}
\end{gathered}
$$

The thermal voltage of the PV cell is described in Equation (6) as follows,

$$
V_{t h}=\frac{k T}{q}
$$

Due to Equation (7), Equation (4) is given by

$$
I=I_{p v}-I_{s}\left(e^{\left[\frac{\left(V+R_{s e} I\right.}{N_{s} V_{t h}^{a}}\right]}-1\right)-\frac{V+R_{s e} I}{R_{s h}}
$$

where $I_{p v, n}$ is the nominal solar PV cell current, $T_{n}$ is the nominal temperature, $\Delta T$ is the deviation from operating temperature $(T), K_{I}$ is the ratio of short circuit current variation to temperature in standard condition, $G_{n}$ is nominal irradiance from solar energy, and $G$ is the irradiance.

$$
I_{s}=\frac{I_{s c, n}+K_{I} \Delta T}{e^{\left(V_{o c, n}+K_{v} \Delta T\right) / a\left(N_{s} k T / q\right)-1}}
$$

where $I_{s c}$, and $V_{o c, n}$ are the short circuit current and open circuit voltage based on nominal operating condition $\left(T_{n}=25^{\circ} \mathrm{C}\right.$ and $\left.G_{n}=1000 \mathrm{~W} / \mathrm{m}^{2}\right)$, and the ratio of the open circuit voltage to temperature is denoted by $K_{v}$. The typical current versus voltage and power versus voltage characteristics curves of the solar PV panel are depicted in Figure 5.

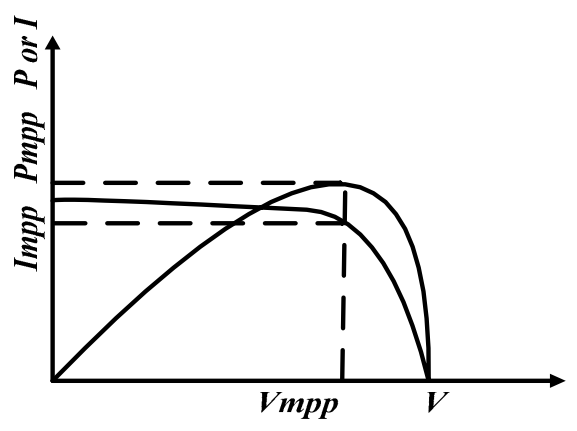

Figure 5. Power vs voltage and current vs voltage characteristics of the PV Cell.

\section{Maximum Power Point Tracking Methods}

The MPPT-based control strategy is employed to extract and maintain the maximum available power from the solar PV tree for varying operating conditions. The MPPT control technique obtains the voltage at which the PV modules are operated at the maximum power point with respect to the load line. Then, the duty cycle for the boost converter is 
generated by utilizing the PWM technique. In this article, a comparative analysis of three MPPT methods is briefly explained.

\subsection{Perturb and Observe Method}

The P\&O algorithm is a conventional method to track the maximum power point. The P\&O method is mostly used for its simple operation and cost-effectiveness. The P\&O-based MPPT method flow chart is shown in Figure 6.

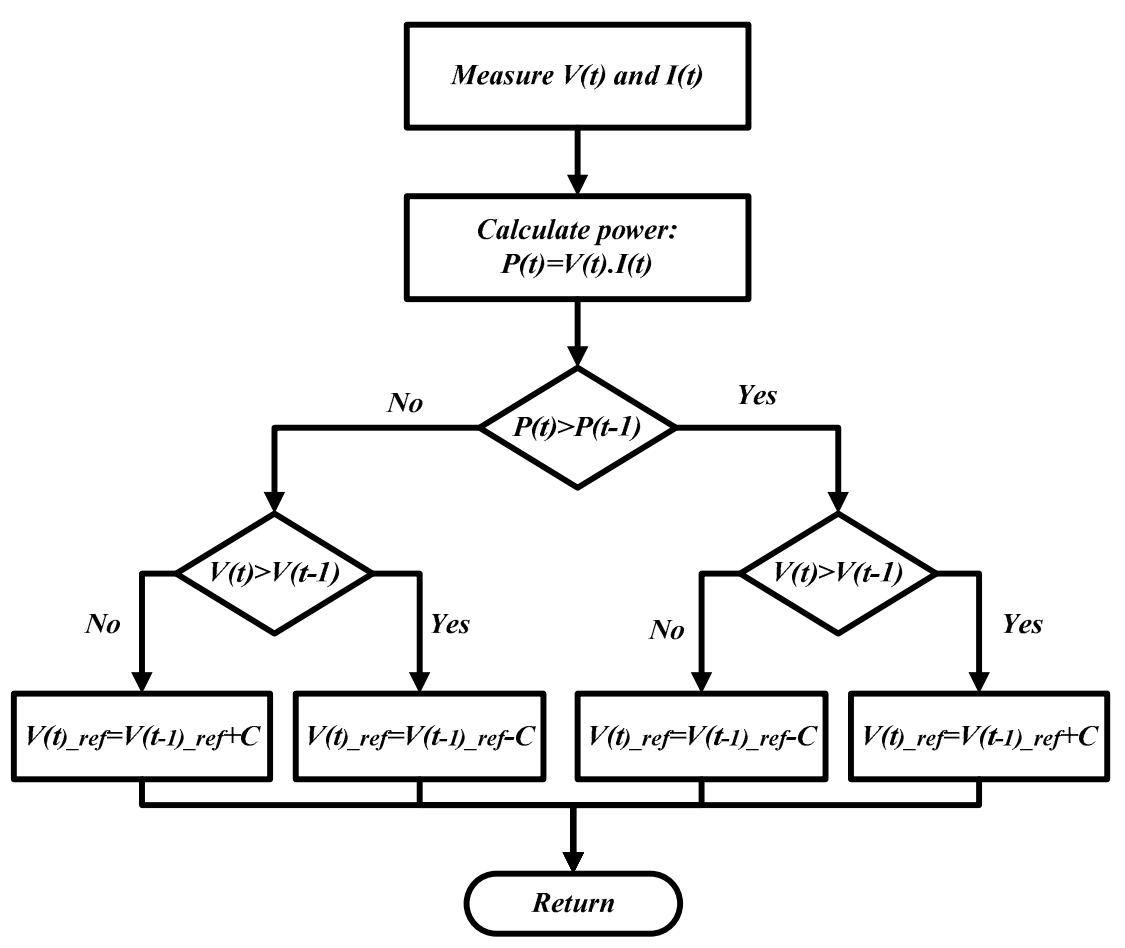

Figure 6. Flowchart of perturb and observe method [1].

The P\&O method works on the principle of measuring the output power variation $(\Delta P)$ during each interval. If $\Delta P$ is positive, the perturbed value $(0.02)$ will be further added until it reaches the maximum power point (MPP). If $\Delta P$ is negative, there will be a change in the direction of the perturbation point, because the point is away from the maximum power point. Hence, the perturb value will be reduced to make the system reach the optimum point [1]. The P\&O algorithm is the simplest method, but it continuously oscillates around the MPP and is not capable of tracking the global peak under partial shading conditions. The oscillation is inevitable due to the nature of the algorithm that forces the operating point to move forward and backward around the MPP with respect to the imposed perturbation. Depending on the size of the perturbation, the oscillation results in a certain amount of power loss. Additionally, the $\mathrm{P} \& \mathrm{O}$ is prone to lose its tracking direction when the irradiance increases rapidly with time. Once the tracking direction is incorrect, the algorithm becomes confused and diverges further away from the MPP. As per the literature, an effective tracking speed of 0.1 to 1 percent of the nominal MPP voltage per second is considered to be sufficient for rapidly changing the irradiance [25].

\subsection{Incremental Conductance Method}

The INC-based MPPT strategy is illustrated as a flowchart in Figure 7, which is designed to locate the maximum power point in the power versus voltage curve. The intention of the INC strategy is to overcome the major concern in the P\&O-based strategym which is the speed of tracking ability of the system. The MPP occurs by differentiating the power from the relationship of voltage and making it zero. Once it attains the MPP, the solar PV tree array operates to keep that optimum point until a change in current 
happens due to environmental conditions. The change in the current parameter will lead to a change in operating point, thus MPP. The INC algorithm makes the corresponding change in set voltage to track the optimum MPP. The step size of the INC determines the efficiency of the system to track the MPP rapidly. Unlike in the P\&O method, the large step size generates oscillations around the maximum power point [8]. The INC algorithm has better ability to find the MPP during sudden changes in irradiance conditions, but it needs a complex controller.

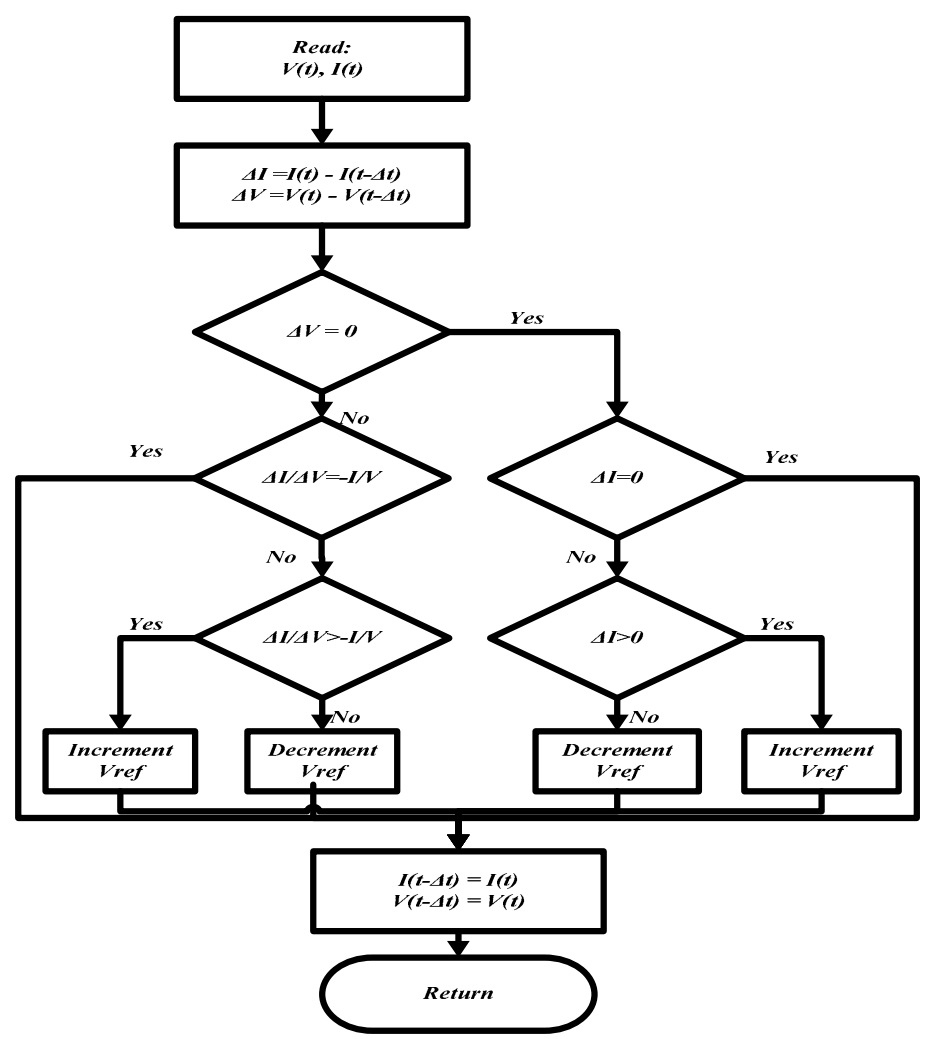

Figure 7. Flowchart of incremental conductance [1].

\subsection{RBFN-Based MPPT Method}

The neural network consists of various types of networks such as RBFN, multi-layer perceptron (MLP), etc. Figure 8 shows the parameter comparison between RBFN and MLP to showcase the effectiveness of the network. From Figure 8, it is evident that the RBFN performance is better than the MLP in all parameters such as training time, learning function, and convergence. Figure 9 shows the computation time between RBFN and MLP for different irradiation values. From Figure 9, it is clearly understood that the RBFN requires less time for computation compared with MLP. Additionally, the RBFN approach requires less time for model development, since no repetition is required. Therefore, the proposed solar PV tree is tested with the RBFN as the MPPT technique, which is used to track the optimum power from the solar modules. The RBFN type of NN algorithm has two stages of process, namely supervised and unsupervised methods. The supervised method is used to train the weights in the hidden layer of the network. The unsupervised methods are used to manage the parameters of the system. 


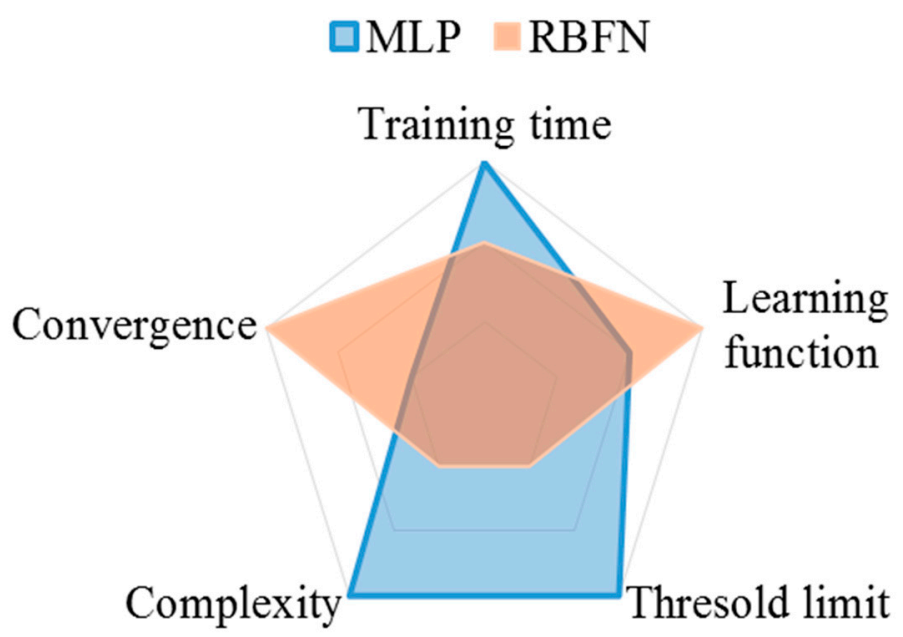

Figure 8. Parameter comparison between RBFN and MLP.

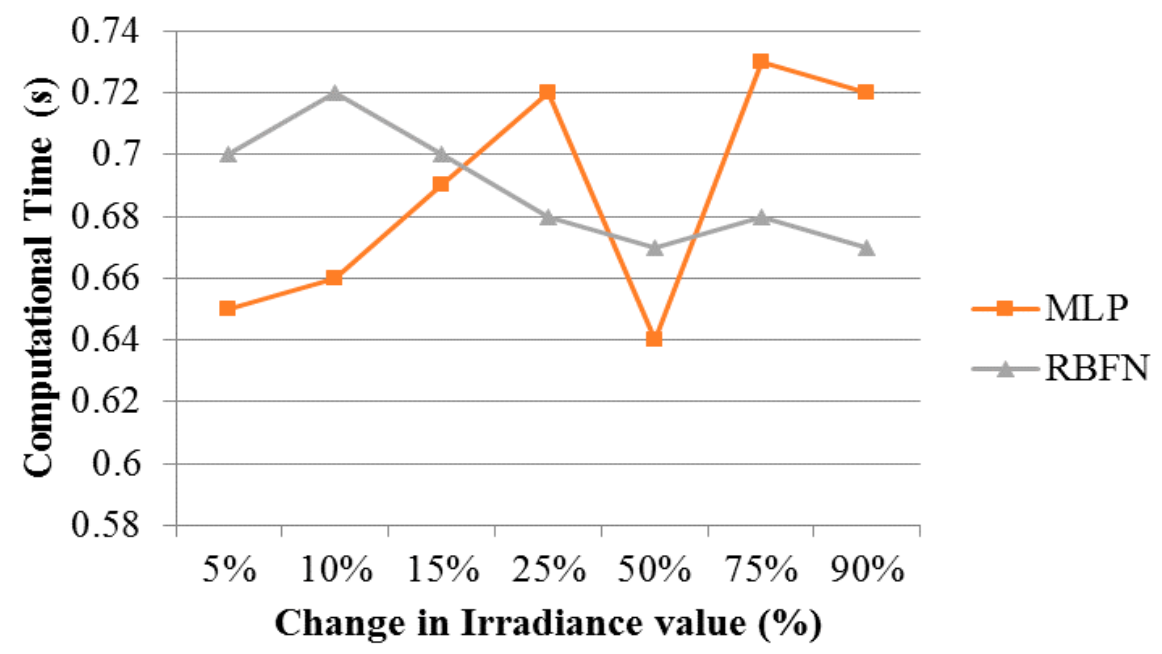

Figure 9. Computation time comparison between RBFN and MLP for different irradiation values.

The RBFN structure is categorized into three layers, input, hidden, and output layers, as shown in Figure 10. The input neurons of the RBFN network are solar PV tree voltage and current, whereas the output neuron is the duty cycle [26,27]. The flowchart for systematic operation of the RBFN network is illustrated in Figure 11. The input layer of the network contains two neurons that are used to send the input data directly (like net input and output) to the subsequent layer; it is represented as

$$
\begin{gathered}
a_{x}^{(1)}(n)=n e t_{x}^{(1)}, \\
b_{x}^{(1)}(n)=f_{x}^{(1)}\left[\operatorname{net}_{x}^{(1)}(n)\right]=n e t_{x}^{(1)}(n), x=1,2
\end{gathered}
$$

where $a_{x}^{(1)}$ is input layer, $b_{x}^{(1)}$ is hidden layer, and net $x^{(1)}$ is sum of input layer with node $x$. Each node of the RBFN network hidden layer is performed by Gaussian membership functions.

$$
\begin{gathered}
\operatorname{net}_{y}^{(2)}(n)=-\left(a-M_{y}\right)^{T} \sum_{y}\left(a-M_{y}\right) \\
b_{y}^{(2)}(n)=f_{y}^{(2)}\left[\operatorname{net}_{y}^{(2)}(n)\right]=\exp \left[\operatorname{net}_{y}^{(2)}(n)\right], y=1,2 \ldots
\end{gathered}
$$

where $M_{y}=\left[m_{1 y}, m_{2 y} \ldots \ldots \ldots m_{x y}\right]^{T}$ and $\sum_{y}=\operatorname{diag}\left[1 / \sigma_{1 y}^{2}, 1 / \sigma_{2 y}^{2} \ldots \ldots \ldots 1 / \sigma_{x y}^{2}\right]^{T}$ are the mean and standard deviation of the Gaussian function, respectively. 


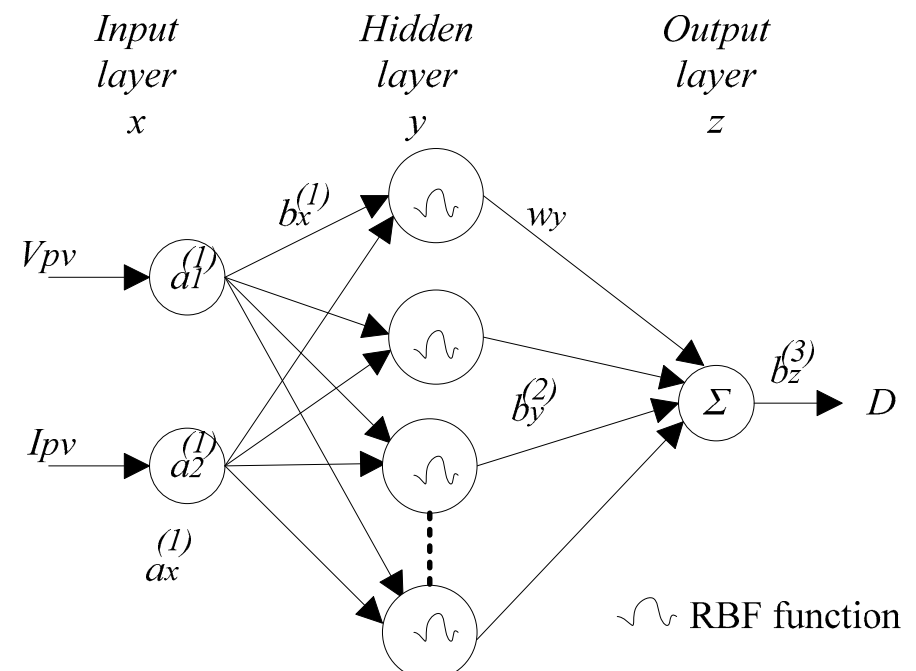

Figure 10. Radial basic function network structure.

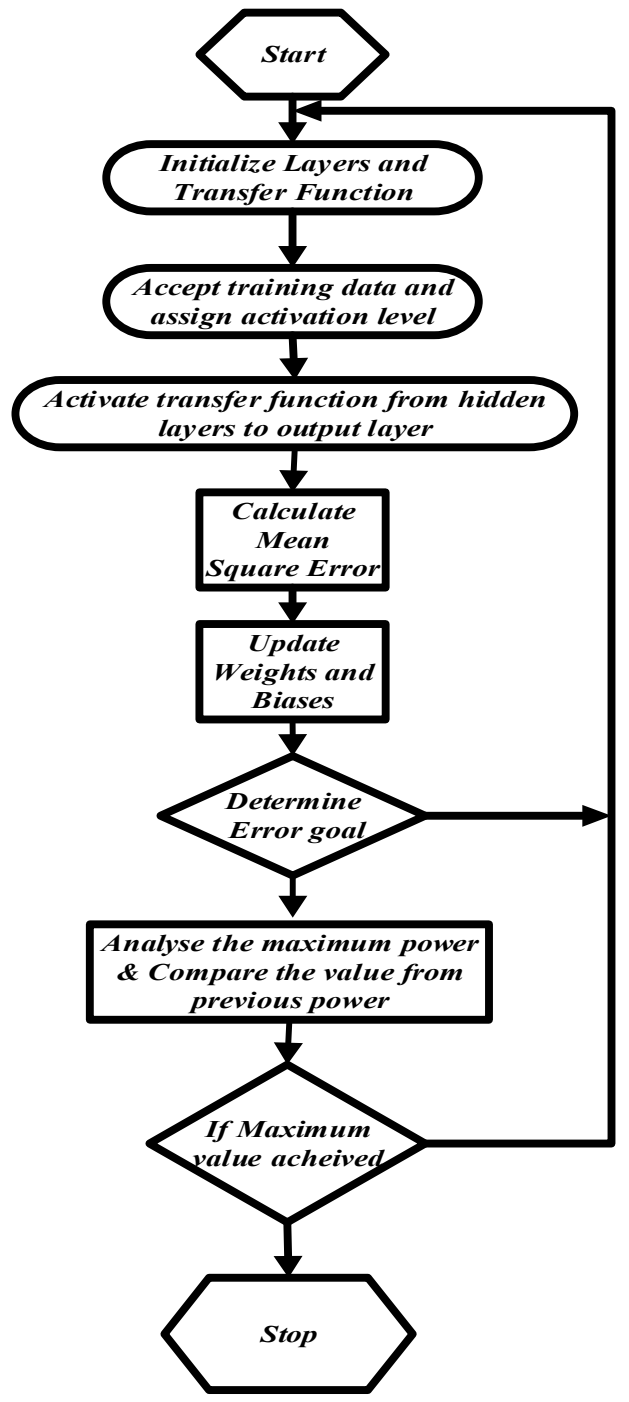

Figure 11. Flowchart for RBFN-Based MPPT technique. 
The output layer contains a single neuron with node $\left(b_{z}\right)$ and produces a linear activation function-based control signal D, as presented in Figure 8. The sum of the incoming signals is computed in the output neuron.

$$
\begin{gathered}
n e t_{z}^{(3)}=\sum_{y} w_{y} b_{y}^{(2)}(n) \\
b_{z}^{(3)}(n)=f_{z}^{(3)}\left\{n e t_{z}^{(3)}(n)\right\}=n e t_{z}^{(3)}(n)
\end{gathered}
$$

where $w_{y}$ is the connective weights between hidden and output layers. The tracking performance of the solar PV tree is enhanced by using the absolute weights for the system [28,29].

\section{Boost Converter}

The converter is the most essential part of generating the step-up voltage acquired from the solar PV tree according to the load demand. Here, the conventional boost converter is employed to produce a required amount of voltage value. The DC-DC boost converter is illustrated in Figure 12, which consists of an inductor $(L)$, capacitor $\left(C_{0}\right)$, diode $(D)$, and single switch $(S)$. When the switch $(S)$ is $\mathrm{ON}$, the direction of the flow of current is from the PV panel $\left(V_{P V}\right)$ to the switch $(S)$ through the inductor $(L)$. The inductor $(L)$ stores energy during this period, and the diode $(D)$ obtains a reverse biased $(R B)$ condition. When the switch $(S)$ is OFF, the diode $(D)$ becomes forward-biased $(F B)$, and the stored energy in the inductor $(L)$ is released. The current takes the path from the solar PV panel $\left(V_{P V}\right)$ to the capacitor $\left(C_{0}\right)$ via the inductor $(L)$ and diode $(D)$ during this period. As a result, the load voltage increases according to the PV panel output voltage. The equations [24] pertaining to the design of the boost converter is given in Table 1. The parameters are estimated through the expressions. Figure 13 shows the Bode plot asymptotes for the magnitude and phase of the proposed converter. The Bode plot is plotted based on the state space equation, which is discussed in [30]. The Bode plot presented in the revised manuscript has the phase margin value of 28 , which is the positive value. Therefore, the bode plot information ensures a stable DC-DC feedback control system. The gain margin at the converter switching frequency is analyzed to ensure that the proposed converter has reduced the gain at that point to prevent instability.

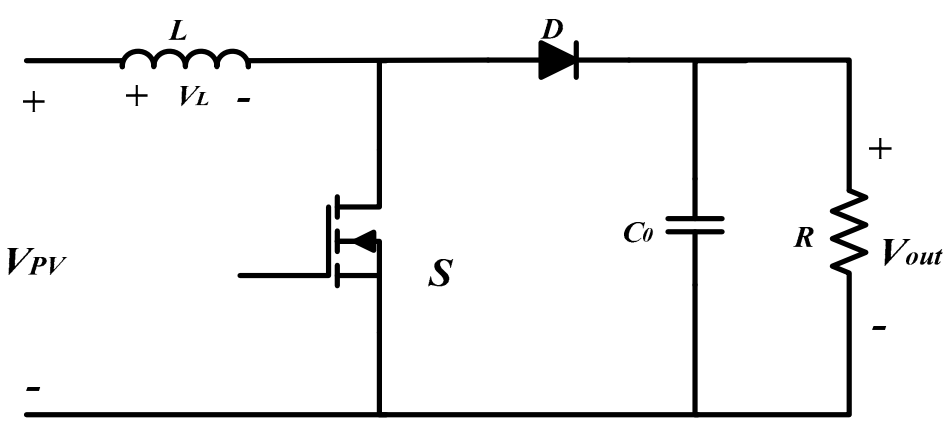

Figure 12. Boost converter circuit diagram.

Table 1. Converter formulas.

\begin{tabular}{cc}
\hline Parameters & Boost Converter \\
\hline Switch duty cycle & $D=1-\frac{V_{\text {in }}}{V_{\text {out }}}$ \\
\hline Inductance & $L=\frac{V_{\text {out }} D}{\Delta \Delta_{L} f}$ \\
\hline Capacitors & $C_{0}=\frac{D}{R\left(\Delta V_{\text {out }} / V_{\text {out }}\right) f}$ \\
\hline
\end{tabular}




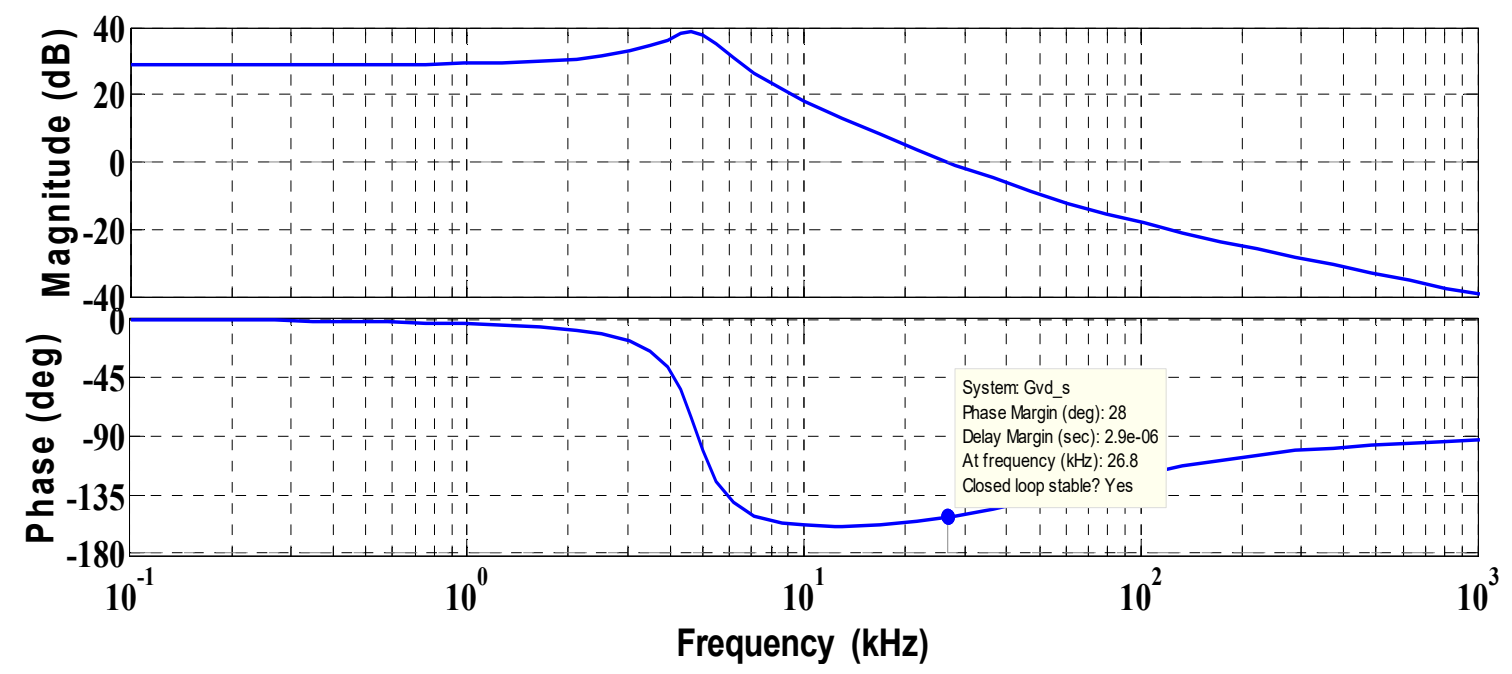

Figure 13. Bode plot for the boost converter in the proposed system.

\section{Result and Discussion}

This section deals with the implementation of proposed solar PV tree using MATLAB for the rating of $1278.18 \mathrm{~W}$ with the individual solar panel capacity of $213.03 \mathrm{~W}$. The performance of the proposed solar PV-tree is tested with the P\&O-, INC-, and RBFN-based MPPT methods for tracking the maximum power in varying environmental condition. The utilized solar PV tree system specification for this work is listed in Table 2. For the solar PV tree, the six PV panels are connected in a tree structure with a different position, which is discussed in Section 2. The solar PV tree consists of three layers in which a single solar module presents in the first layer, two solar modules present in the second layer, and three solar modules present in the third layer. The boost converter is used in this work to step-up the solar PV tree voltage. The parameters, such as $V_{\text {in }}=26.3 \mathrm{~V}, V_{\text {out }}=260 \mathrm{~V}$, duty cycle $=0.9, L=1.93 \mathrm{mH}$, and $C_{o}=128 \mu \mathrm{F}$, are used in the simulation. The switching frequency used in the proposed system is $24 \mathrm{kHz}$. The orthogonal least squares (OLS) learning algorithm is employed to train the RBFN. The variation of the spread constant is taken as the key deciding factor for RBFN performance. The 3000 data sets have been taken from the PV panel (i.e., voltage and current) under varying irradiation conditions for training the NN. These values are considered the input of the neurons, whereas the duty cycle is considered the output of the neurons. The duty cycle has been decided based on the boost converter gain, voltage, and current values of PV panel. The solar PV-tree along with different MPPT techniques, namely P\&O-, INC-, and RBFN-based DC-DC boost converters, are tested separately, and the results are compared for both constant and variable irradiance conditions with constant temperature.

Table 2. Solar PV tree specification at standard operating condition.

\begin{tabular}{cc}
\hline Parameters & Value \\
\hline \multicolumn{2}{c}{ Single PV panel capacity } \\
\hline Solar PV tree capacity power & $1278.18 \mathrm{~W}$ \\
\hline Maximum Power, $P_{M P P}$ & $213.03 \mathrm{~W}$ \\
\hline No. of PV Panels & 6 Parallel connection \\
\hline Maximum current, $I_{M P P}$ & $8.12 \mathrm{~A}$ \\
\hline
\end{tabular}

\subsection{Constant Irradiance Condition}

In this analysis, both the irradiance and temperature are considered as constant for the solar PV tree. The boost converter output and power output of the solar PV tree system using P\&O, INC, and RBFN are depicted in Figure 14a,b. The output power of the proposed 
solar PV tree system for the constant irradiance condition is tabulated in Table 3. Simulation results show that the output power generated using P\&O-, INC-, and RBFN-based MPPT algorithms is $870.6,887.8$, and $1009 \mathrm{~W}$ respectively. From the results, it is clearly shown that the RBFN-based PV system generates better power than the other MPPT methods.

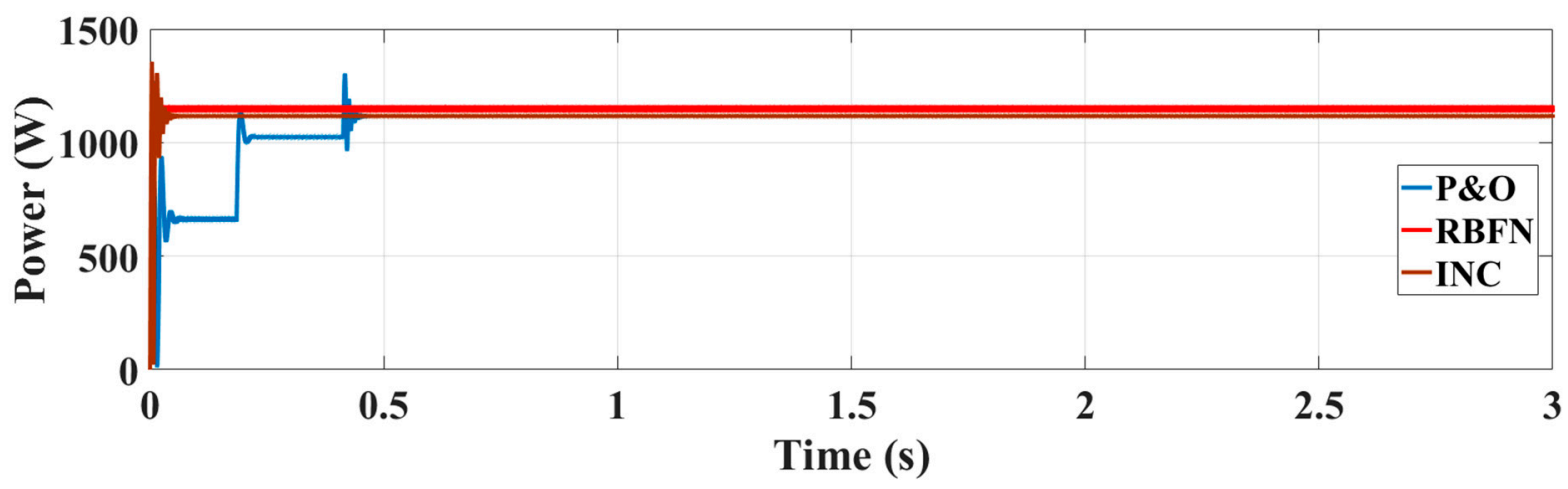

(a)

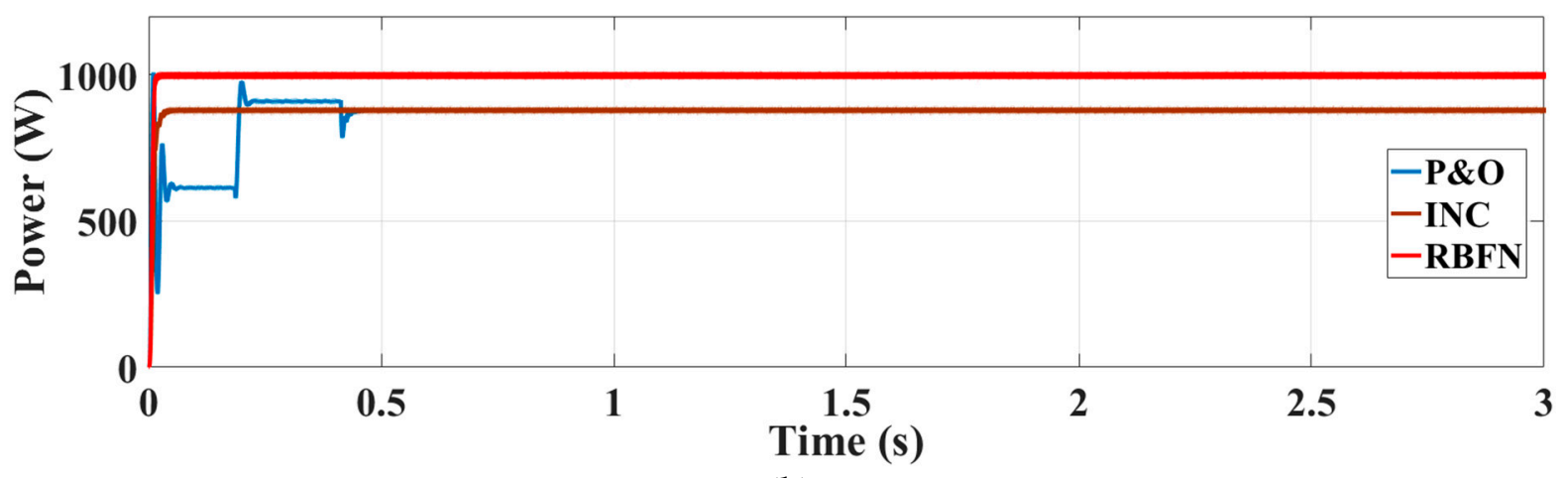

(b)

Figure 14. Constant irradiance condition, (a) solar PV tree output power, and (b) boost converter output power.

Table 3. Comparison of solar PV tree maximum power based on MPPT techniques and boost converter.

\begin{tabular}{|c|c|c|}
\hline \multirow{4}{*}{ MPPT Techniques } & \multicolumn{2}{|c|}{ Boost Converter } \\
\hline & \multicolumn{2}{|c|}{$1000 \mathrm{~W} / \mathrm{m}^{2}$} \\
\hline & \multicolumn{2}{|c|}{ Power (W) } \\
\hline & PV Tree & $\mathbf{P}_{\text {OUT }}$ \\
\hline $\mathrm{P \& O}$ & 1116 & 870.6 \\
\hline INC & 1124 & 887.8 \\
\hline RBFN & 1163 & 1009 \\
\hline
\end{tabular}

\subsection{Variable Irradiance Condition}

The proposed system is also validated by varying the irradiance level of the PV system with a constant temperature for calculating the performance evaluation. The different levels of irradiance range between $450-1000 \mathrm{~W} / \mathrm{m}^{2}$ values for six PV panels under $0.5 \mathrm{~s}$ variation, which are shown in Table 4 and Figure 15. The duty cycle and PWM of the proposed system for the corresponding irradiance are shown in Figure 16. Figure 17a,b illustrates the solar PV tree output power and boost converter output power for the different MPPT techniques. The power output of the solar PVtree for different irradiance conditions is listed in Table 5. From the simulation results, the P\&O- and INC-based MPPT produce the output power of 842.8 and $844.8 \mathrm{~W}$, whereas the RBFN-based MPPT method generates 895.4 W output power during the $0-0.5 \mathrm{~s}$ period with the lesser oscillation. 
Table 4. Comparison of various irradiance levels for six PV panels.

\begin{tabular}{|c|c|c|c|c|c|c|}
\hline \multirow{2}{*}{ PV Panels } & \multicolumn{6}{|c|}{ Irradiance $\left(\mathrm{W} / \mathrm{m}^{2}\right)$} \\
\hline & $(0-0.5) \mathrm{s}$ & $(0.5-1) \mathrm{s}$ & $(1-1.5) \mathrm{s}$ & $(1.5-2) \mathrm{s}$ & $(2-2.5) \mathrm{s}$ & $(2.5-3) \mathrm{s}$ \\
\hline 1 & 1000 & 950 & 900 & 800 & 850 & 700 \\
\hline 2 & 1000 & 750 & 950 & 850 & 700 & 800 \\
\hline 3 & 800 & 950 & 1000 & 850 & 750 & 900 \\
\hline 4 & 850 & 800 & 900 & 600 & 700 & 750 \\
\hline 5 & 700 & 550 & 600 & 650 & 500 & 750 \\
\hline 6 & 600 & 650 & 550 & 700 & 450 & 500 \\
\hline
\end{tabular}

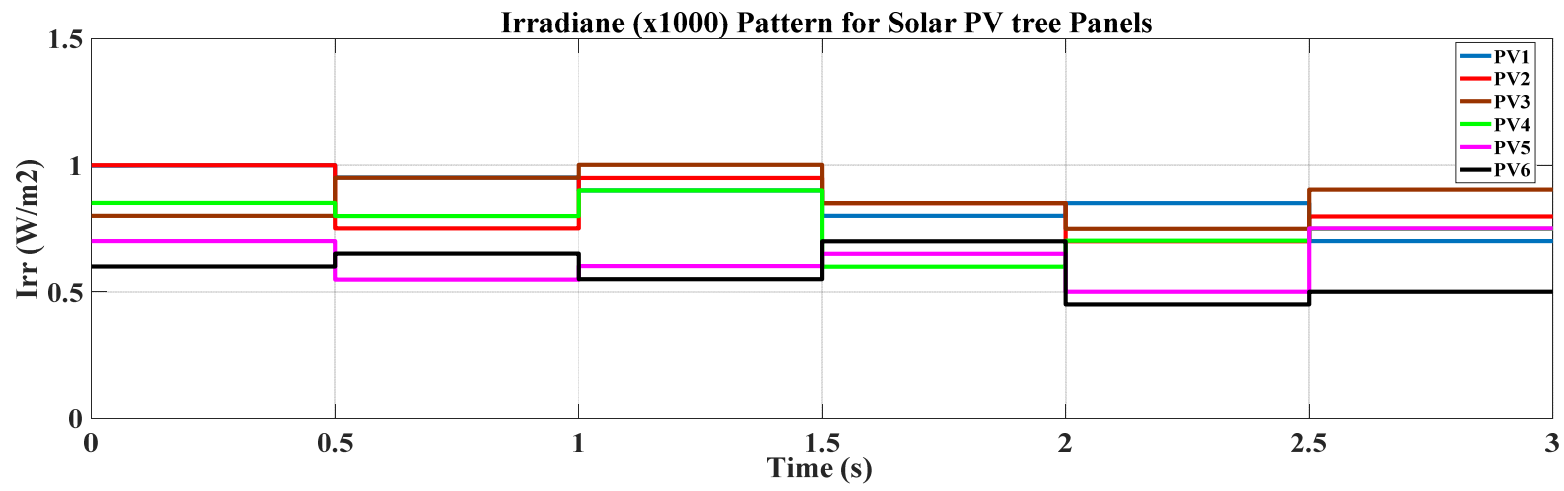

Figure 15. Different irradiance level of six PV panels.
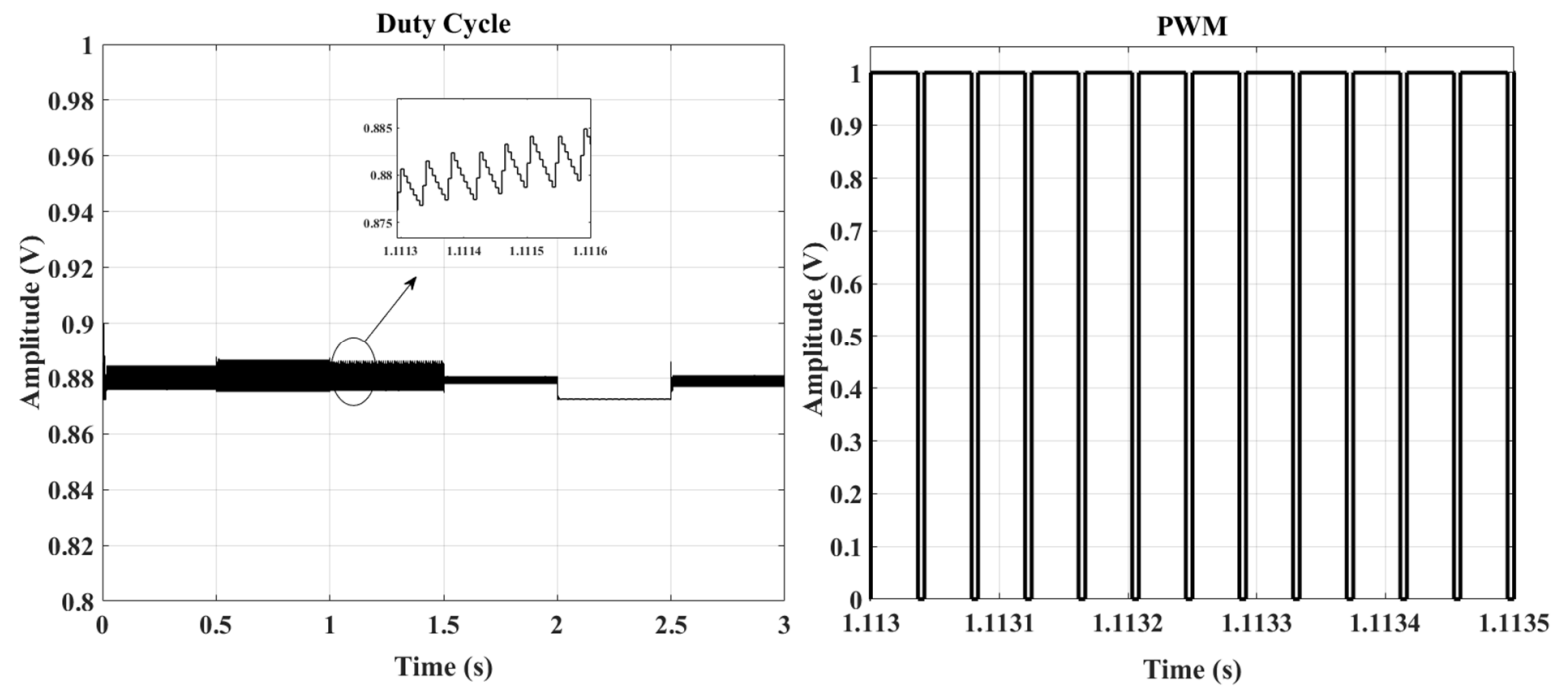

Figure 16. RBFN duty cycle and PWM pulses.

The analysis of the proposed method is carried out further for each layer of solar modules in the solar tree structure. The performance of all six PV panels in the solar PV tree using P\&O, INC, and RBFN MPPT methods is illustrated in the Tables 6-8. The proposed solar PV tree using P\&O-based MPPT to track the maximum power under varying irradiance conditions is depicted in Figure 18, and the performance results are given in Table 6. The output power produced by one of the solar modules is $197.4 \mathrm{~W}$ when the irradiance level is $1000 \mathrm{~W} / \mathrm{m}^{2}$ and $77.3 \mathrm{~W}$ under $450 \mathrm{~W} / \mathrm{m}^{2}$ irradiance conditions. The simulation result clearly reveals that the P\&O-based MPPT method produces more oscillation during the changes in irradiance condition, whereas the constant value is for the standard irradiance condition. 


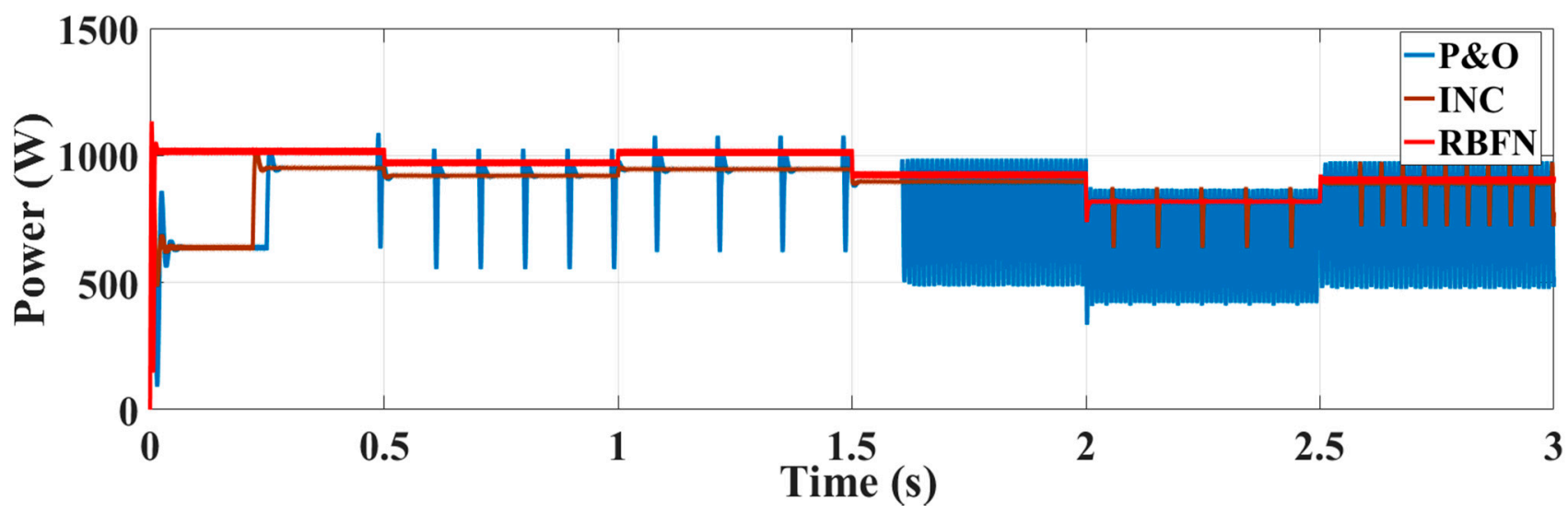

(a)

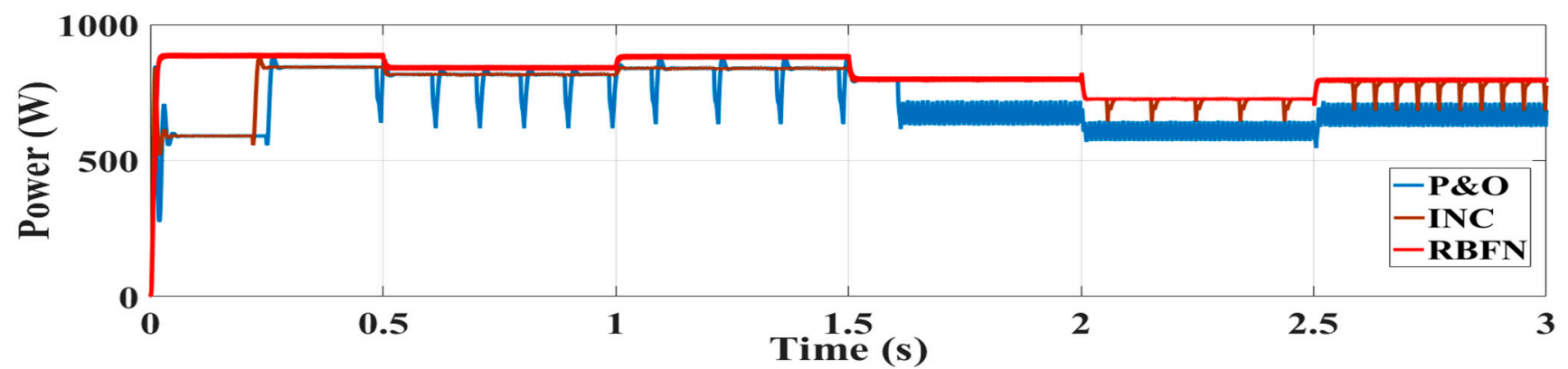

(b)

Figure 17. Varying irradiance condition (a) solar PV tree output power, and (b) boost converter output power.

Table 5. Comparison table of maximum power of solar PV tree-based on MPPT techniques and converter output power under varying condition.

\begin{tabular}{|c|c|c|c|c|c|c|c|c|c|c|c|c|}
\hline \multirow{4}{*}{ MPPT Techniques } & \multicolumn{12}{|c|}{ Boost Converter } \\
\hline & \multirow{2}{*}{\multicolumn{2}{|c|}{$\begin{array}{c}(0-0.5) \mathrm{s} \\
\text { Power }(\mathrm{W})\end{array}$}} & \multirow{2}{*}{\multicolumn{2}{|c|}{$\begin{array}{c}(0.5-1) \mathrm{s} \\
\text { Power }(\mathrm{W})\end{array}$}} & \multirow{2}{*}{\multicolumn{2}{|c|}{$\begin{array}{c}(1-1.5) \mathrm{s} \\
\text { Power }(W)\end{array}$}} & \multirow{2}{*}{\multicolumn{2}{|c|}{$\begin{array}{c}(1.5-2) \mathrm{s} \\
\text { Power }(W)\end{array}$}} & \multirow{2}{*}{\multicolumn{2}{|c|}{$\begin{array}{c}(2-2.5) \mathrm{s} \\
\text { Power }(\mathrm{W})\end{array}$}} & \multirow{2}{*}{\multicolumn{2}{|c|}{$\begin{array}{c}(2.5-3) \mathrm{s} \\
\text { Power }(\mathrm{W})\end{array}$}} \\
\hline & & & & & & & & & & & & \\
\hline & PV Tree & $P_{\text {OUT }}$ & PV Tree & Pout & PV Tree & $P_{\text {OUT }}$ & PV Tree & $P_{\text {OUT }}$ & PV Tree & $P_{\text {OUT }}$ & PV Tree & $P_{\text {OUT }}$ \\
\hline $\mathrm{P} \& \mathrm{O}$ & 953.2 & 842.8 & 917.2 & 820.7 & 944 & 835.8 & 802.1 & 688.9 & 673.2 & 619.1 & 777.3 & 682.3 \\
\hline INC & 957.1 & 844.8 & 922.5 & 820.7 & 952.3 & 843.3 & 903.2 & 799.7 & 814.2 & 727.6 & 893 & 794.1 \\
\hline RBFN & 1023 & 895.4 & 967.3 & 850.8 & 1014 & 890.9 & 930.9 & 809.1 & 824.1 & 729.6 & 917.5 & 802.1 \\
\hline
\end{tabular}

Table 6. Comparison of solar PV tree modules' maximum power based on P\&O MPPT technique under varying conditions.

\begin{tabular}{|c|c|c|c|c|c|c|}
\hline \multirow{3}{*}{ PV Panels } & \multicolumn{6}{|c|}{ P\&O-Based MPPT } \\
\hline & $(0-0.5) \mathrm{s}$ & $(0.5-1) \mathrm{s}$ & $(1-1.5) \mathrm{s}$ & $(1.5-2) \mathrm{s}$ & $(2-2.5) \mathrm{s}$ & $(2.5-3) \mathrm{s}$ \\
\hline & POUT1 (W) & $P_{\text {OUT2 }}(\mathrm{W})$ & POUT3 $_{\text {OW) }}$ & POUT4 $(\mathrm{W})$ & POUT5 $(W)$ & $P_{\text {OUT6 }}(\mathrm{W})$ \\
\hline 1 & 196.4 & 192.8 & 175.6 & 135.4 & 149.1 & 120.9 \\
\hline 2 & 195.2 & 148.2 & 185.5 & 139.4 & 118.1 & 134 \\
\hline 3 & 154.1 & 192.6 & 197.4 & 148.3 & 127 & 150.1 \\
\hline 4 & 165.1 & 159.7 & 176.8 & 104.5 & 118.6 & 128.1 \\
\hline 5 & 132.3 & 104.5 & 111.6 & 109.9 & 83.14 & 127.8 \\
\hline 6 & 110 & 127.2 & 100.3 & 119.1 & 77.3 & 84.62 \\
\hline
\end{tabular}


Table 7. Comparison of solar PV tree modules' maximum power based on INC MPPT technique under varying conditions.

\begin{tabular}{|c|c|c|c|c|c|c|}
\hline \multirow{3}{*}{ PV Panels } & \multicolumn{6}{|c|}{ INC-Based MPPT } \\
\hline & $(0-0.5) \mathrm{s}$ & $(0.5-1) \mathrm{s}$ & $(1-1.5) \mathrm{s}$ & $(1.5-2) \mathrm{s}$ & $(2-2.5) \mathrm{s}$ & $(2.5-3) \mathrm{s}$ \\
\hline & $P_{\text {OUT1 }}(W)$ & $P_{\text {OUT2 }}(W)$ & $P_{\text {OUT3 }}(W)$ & $P_{\text {OUT4 }}(\mathrm{W})$ & $P_{\text {OUT5 }}(\mathrm{W})$ & $P_{\text {OUT6 }}(\mathrm{W})$ \\
\hline 1 & 197 & 192.8 & 176.8 & 162.6 & 178.9 & 142.1 \\
\hline 2 & 196.2 & 148.2 & 187.3 & 174.2 & 146.1 & 162.4 \\
\hline 3 & 154.1 & 190.9 & 197.9 & 173.1 & 157 & 185.5 \\
\hline 4 & 165 & 159.7 & 176.8 & 119.1 & 146.8 & 151 \\
\hline 5 & 130.5 & 102.7 & 111.7 & 130.3 & 102.1 & 153.1 \\
\hline 6 & 110.5 & 126.5 & 100.3 & 141.1 & 91.5 & 97.91 \\
\hline
\end{tabular}

Table 8. Comparison of solar PV tree modules' maximum power based on RBFN MPPT technique under varying conditions.

\begin{tabular}{|c|c|c|c|c|c|c|}
\hline \multirow{3}{*}{ PV Panels } & \multicolumn{6}{|c|}{ RBFN-Based MPPT } \\
\hline & $(0-0.5) \mathrm{s}$ & $(0.5-1) \mathrm{s}$ & $(1-1.5) \mathrm{s}$ & $(1.5-2) \mathrm{s}$ & $(2-2.5) \mathrm{s}$ & $(2.5-3) \mathrm{s}$ \\
\hline & $P_{\text {OUT1 }}(\mathrm{W})$ & $P_{\text {OUT2 }}(\mathrm{W})$ & $P_{\text {OUT3 }}(\mathrm{W})$ & $P_{\text {OUT4 }}(\mathrm{W})$ & $P_{\text {OUT5 }}(\mathrm{W})$ & $P_{\text {OUT6 }}(\mathrm{W})$ \\
\hline 1 & 209.2 & 199.6 & 188.9 & 168.1 & 178.9 & 145.3 \\
\hline 2 & 205.4 & 154.6 & 199.5 & 177.5 & 144.6 & 166.1 \\
\hline 3 & 162 & 200 & 209.1 & 178.5 & 157 & 185.9 \\
\hline 4 & 174.1 & 166.8 & 185.9 & 125.6 & 146.8 & 154.8 \\
\hline 5 & 143.3 & 111.6 & 123.4 & 136.4 & 102.6 & 156.3 \\
\hline 6 & 121.9 & 136.5 & 112 & 146.9 & 91.79 & 100.3 \\
\hline
\end{tabular}
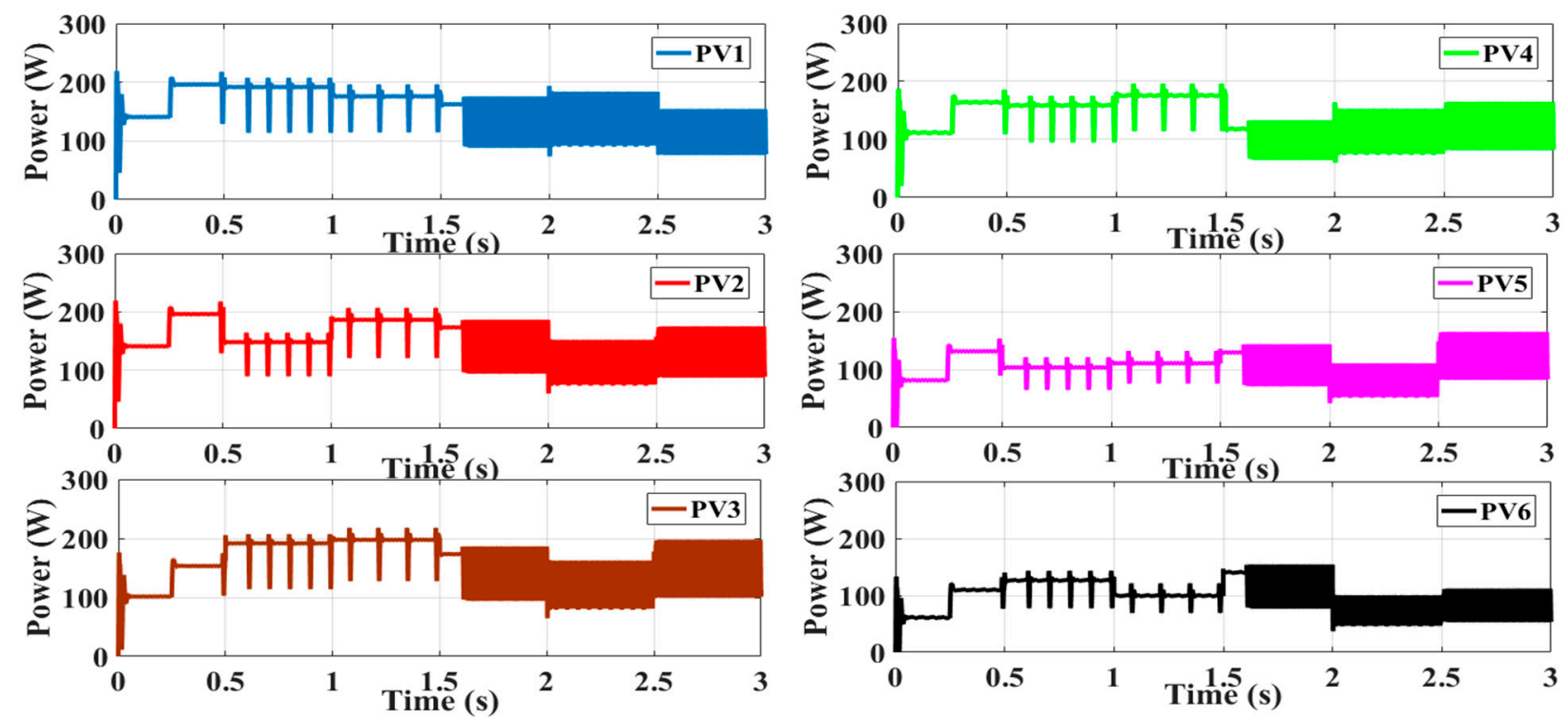

Figure 18. Solar PV tree panel-based P\&O MPPT method under varying irradiance condition.

The same type of analysis is also performed for the INC-based MPPT technique, and the results are shown in Figure 19 and Table 7 . This method gives the output power of 197.9 and $91.5 \mathrm{~W}$ for 1000 and $450 \mathrm{~W} / \mathrm{m}^{2}$ irradiance condition, respectively. By comparing the obtained results from $\mathrm{P} \& \mathrm{O}$ and INC method, it is visibly seen that the INC-based MPPT technique tracks the optimum power with lesser oscillation nature than the $\mathrm{P} \& \mathrm{O}$ technique. 

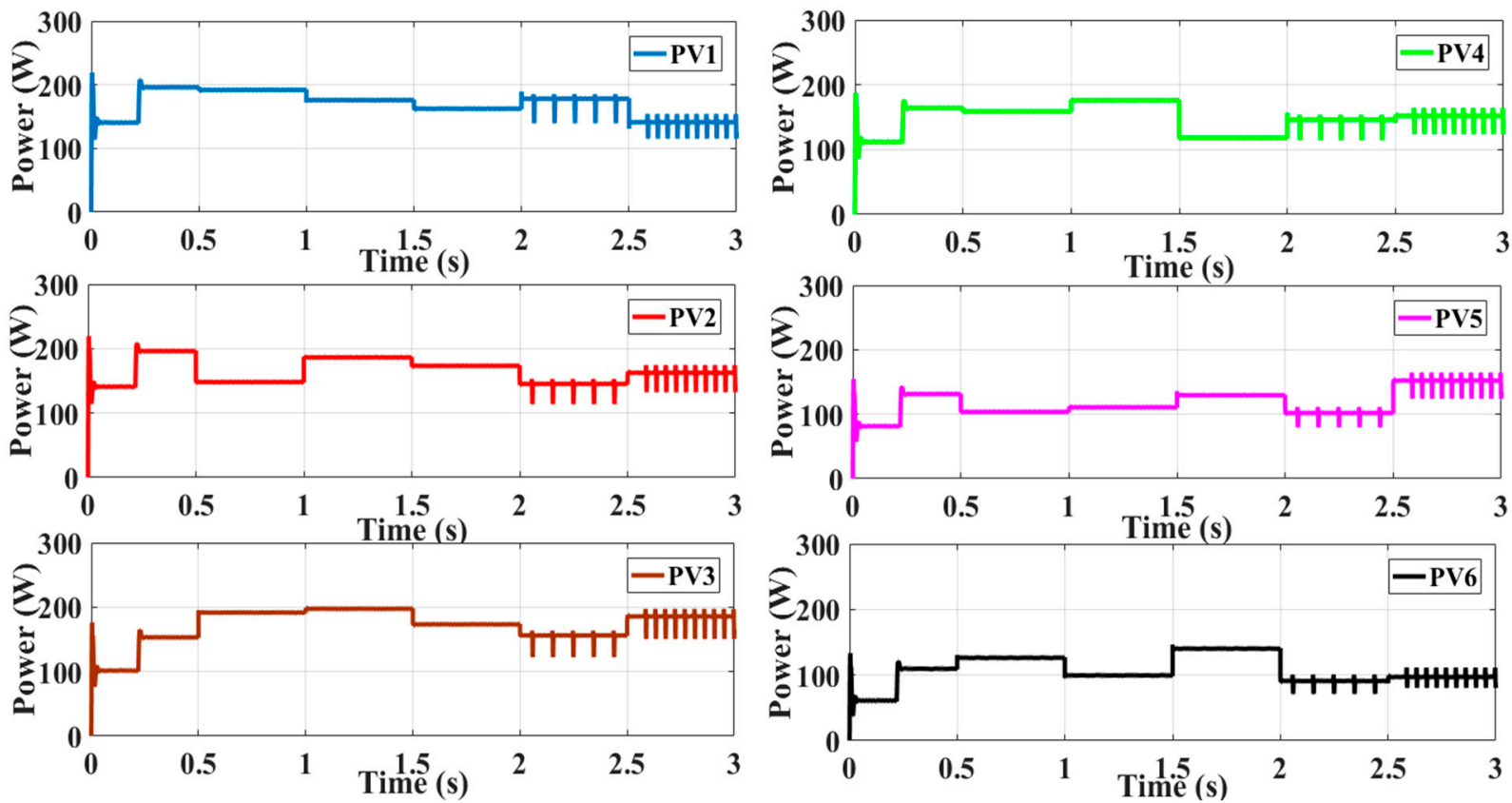

Figure 19. Solar PV tree panel-based INC MPPT method under varying irradiance condition.

The simulation results are obtained with a similar type of analysis for the RBFN-based MPPT technique, which are given in Figure 20. and Table 8. In this method, the maximum power of $209.2 \mathrm{~W}$ is generated during the standard irradiance condition and $191.79 \mathrm{~W}$ is generated at $450 \mathrm{~W} / \mathrm{m}^{2}$ irradiance condition. From the simulation results of all the three methods, it is concluded that the RBFN-MPPT technique with DC-DC boost converter gives the best tracking rather than the other two algorithms.
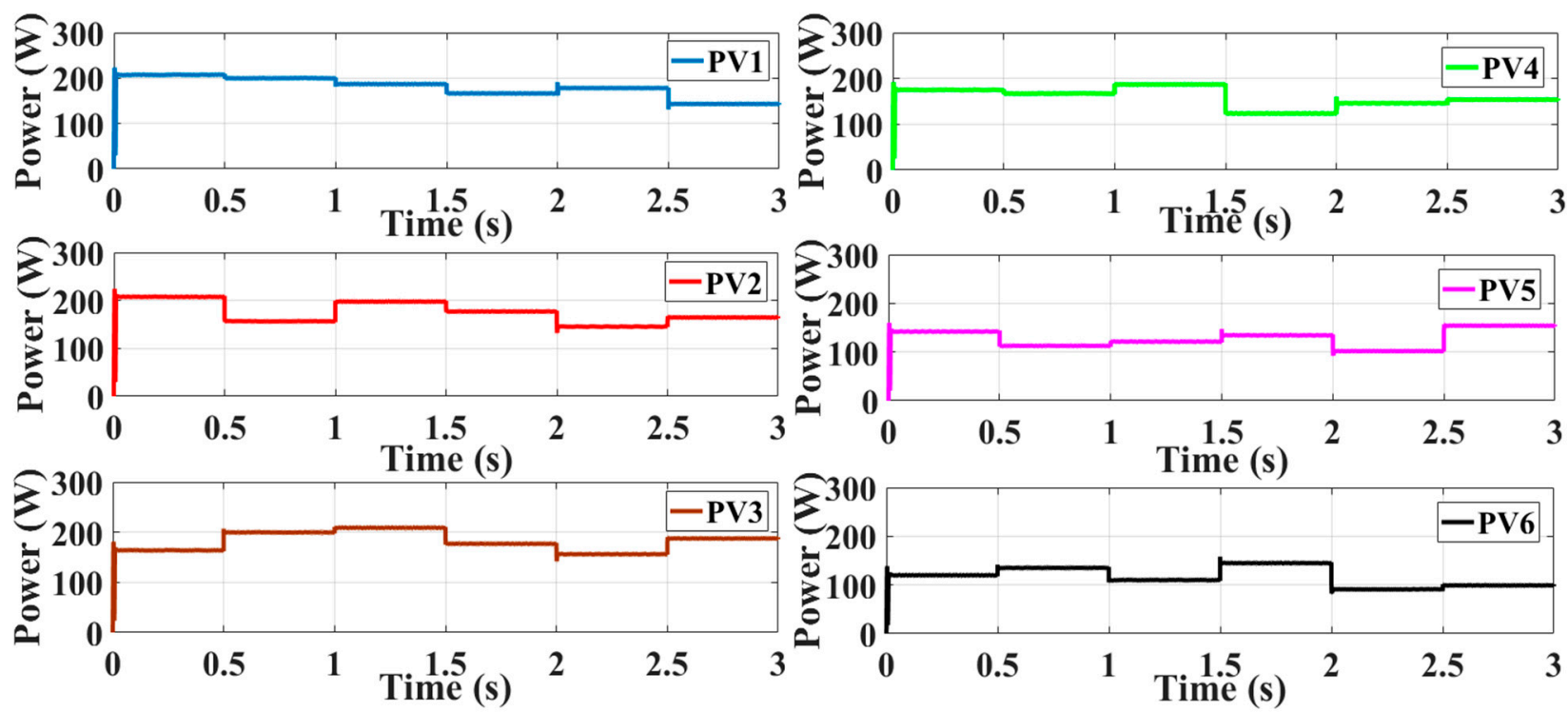

Figure 20. Solar PV tree panel-based RBFN MPPT method under varying irradiance condition.

\subsection{Hardware Implementation}

The real time implementation of the solar tree is shown to validate the performance of the proposed MPPT strategy, as shown in Figure 21. The solar tree consists of a 16 PV array connected in an Eight Series-Eight Parallel configuration. The total power generated from the PV is $1.2 \mathrm{~kW}$. A dSPACE real time controller is used in this work to generate the 
gate pulses to the converter switch with a signal frequency of $24 \mathrm{kHz}$. A boost type dc/dc converter is used to amplify the input voltage to the desired level.

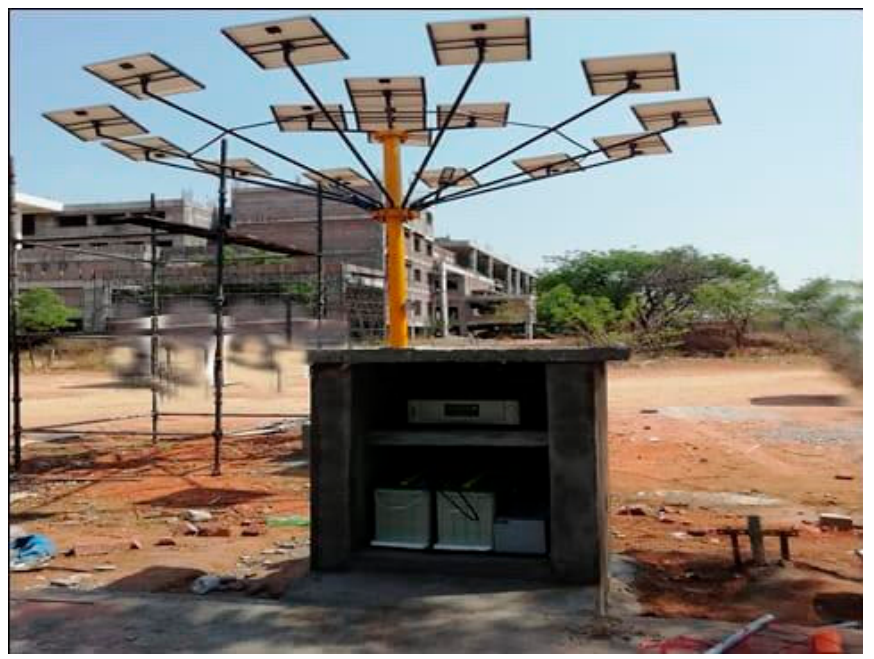

Figure 21. Real time implementation of solar tree.

Two different modes of partial shading conditions are considered to verify the proposed MPPT method experimentally in varying weather conditions. The results of these conditions are as illustrated in Figures 22-24. Figure 22 shows the experimental results of the system with the P\&O-based MPPT technique. The entire tracking process in the $\mathrm{P} \& \mathrm{O}-$ based MPPT technique takes more time to reach the maximum power point (MPP). The power obtained from the boost converter by implementing the P\&O-based control strategy are $284 \mathrm{~W}$ for $600 \mathrm{~W} / \mathrm{m}^{2}$ and $722 \mathrm{~W}$ for $900 \mathrm{~W} / \mathrm{m}^{2}$.

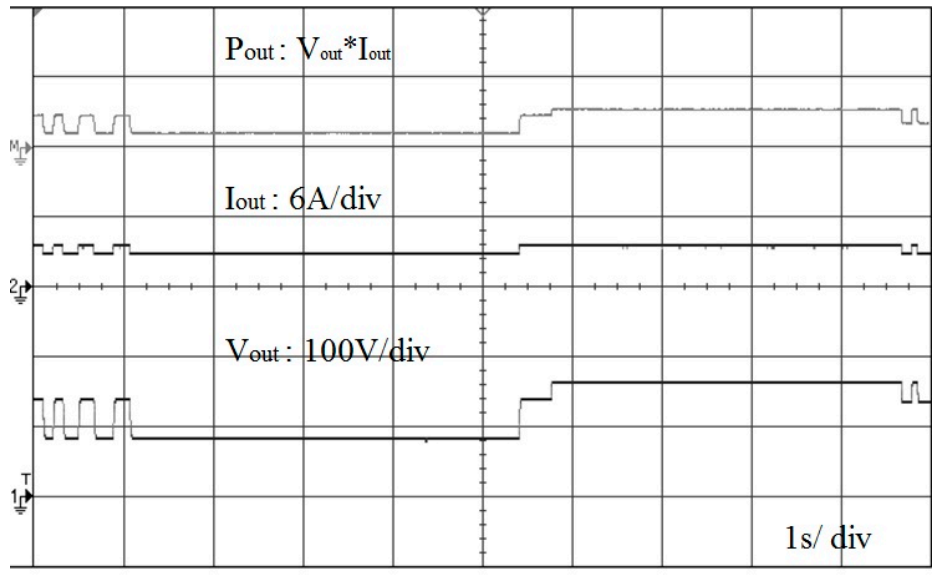

Figure 22. Experimental output of $\mathrm{P} \& \mathrm{O}$-based MPPT control strategy.

The experimental results of the INC-based MPPT technique are shown in Figure 23. The power output of the boost converter obtained by using the INC-based MPPT strategy is $432 \mathrm{~W}$ for $600 \mathrm{~W} / \mathrm{m}^{2}$ and $828 \mathrm{~W}$ for $900 \mathrm{~W} / \mathrm{m}^{2}$. The INC method performs better than the $\mathrm{P} \& \mathrm{O}-$ based control technique in terms of extracting maximum power. Nevertheless, the INC method lacks minimization of the convergence speed to track the maximum power and oscillates around the MPP for a longer time.

To overcome the above said two limitations, an RBFN-based control technique is proposed in this work. The experimental results of the RBFN-based control strategy are shown in Figure 24. The RBFN-based MPPT technique is faster in terms of tracking the MPP, thus eliminating the oscillation during partial shading condition. The power output 
obtained using the proposed MPPT technique is $540 \mathrm{~W}$ for $600 \mathrm{~W} / \mathrm{m}^{2}$ and $942 \mathrm{~W}$ for $900 \mathrm{~W} / \mathrm{m}^{2}$. The RBFN-based MPPT technique is the most suitable MPPT strategy for varying weather conditions.

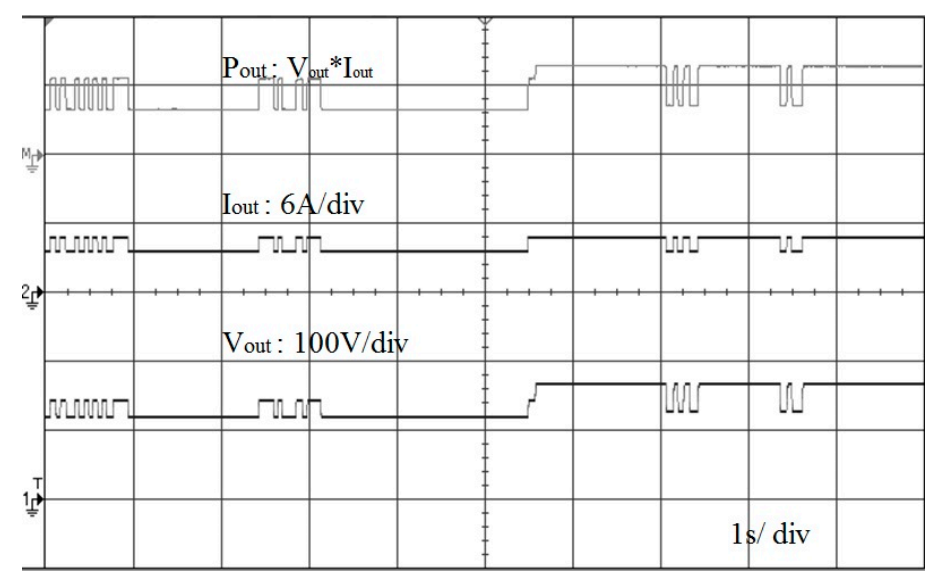

Figure 23. Experimental output of INC-based MPPT control strategy.

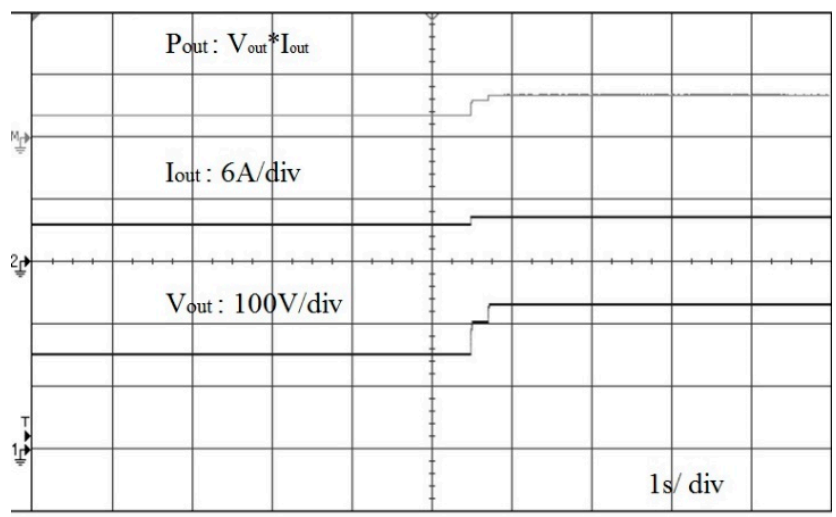

Figure 24. Experimental output of proposed RBFN-based MPPT control strategy.

\section{Conclusions}

This work proposed the design of a solar PV tree-based energy harvesting system at different angles under constant temperature and varying irradiance conditions. To extract the maximum power, 3-MPPT techniques such as P\&O, INC, and RBFN with a boost converter have been implemented, and their results have been compared with each other. The modeling and simulation of the proposed system have been done using MATLAB software, and their results has been verified using a real-time prototype. From the simulation and experimental results, it is evident that the RBFN-MPPT technique provides better results when compared to other MPPT techniques such as P\&O and INC. The RBFNMPPT provides a significant improvement in tracking efficiency of $6.0 \%$ and $5.72 \%$ as compared with the $\mathrm{P} \& \mathrm{O}$ method and the INC method at $1000 \mathrm{~W} / \mathrm{m}^{2}$ irradiance condition. From the simulation and experimental results, it can be concluded that the proposed control strategy not only extracts the maximum power but also limits the oscillation of output variable near MPP. Due to the inherent property of the actual mapping, the tracking efficiency in RBFN method is high compared to the other two methods.

Author Contributions: Conceptualization, P.P.; S.S.; R.T.; and T.C.; methodology, S.S.; and N.R.B.; software, S.S.; validation, S.S., N.P. and R.T.; formal analysis, P.P.; and S.S.; investigation, S.S.; and N.P.; writing—original draft preparation, P.P.; S.S.; and N.P.; writing—review and editing, S.S.; and N.P.; supervision, N.P.; N.R.B.; and E.H. All authors have read and agreed to the published version of the manuscript. 
Funding: This research received no external funding.

Institutional Review Board Statement: Not applicable.

Informed Consent Statement: Not applicable.

Data Availability Statement: Data available on request due to privacy/ethical restrictions.

Conflicts of Interest: The authors declare no conflict of interest.

\section{References}

1. Saravanan, S.; Ramesh Babu, N. Maximum power point tracking algorithms for photovoltaic system-A review. Renew. Sustain. Energy Rev. 2016, 57, 192-204. [CrossRef]

2. Hyder, F.; Sudhakar, K.; Mamat, R. Solar PV tree design: A review. Renew. Sustain. Energy Rev. 2018, 82, 1079-1096. [CrossRef]

3. Khan, H.; Gaur, P. Design of solar tree with photovoltaic panels using Fibonacci pattern. Adv. Res. Electr. Electron. Eng. 2015, 2, 67-71.

4. Hyder, F.; Baredar, P.; Sudhakar, K.; Mamat, R. Performance and land footprint analysis of a solar photovoltaic tree. J. Clean. Prod. 2018, 187, 432-448. [CrossRef]

5. Ahmed, R.; Kim, Y.; Zeeshan; Chun, W. Development of a Tree-Shaped Hybrid Nanogenerator Using Flexible Sheets of Photovoltaic and Piezoelectric Films. Energies 2019, 12, 229. [CrossRef]

6. Gangwar, P.; Singh, R.; Tripathi, R.P.; Singh, A.K. Effective solar power harnessing using a few novel solar tree designs and their performance assessment. Energy Sources Part A Recovery Util. Environ. Eff. 2018, 41, 1828-1837. [CrossRef]

7. Elgendy, M.A.; Zahawi, B.; Atkinson, D.J. Assessment of Perturb and Observe MPPT Algorithm Implementation Techniques for PV Pumping Applications. IEEE Trans. Sustain. Energy 2012, 3, 21-33. [CrossRef]

8. Pazhampilly, R.; Saravanan, S.; Babu, N.R. Incremental conductance based MPPT for PV system using boost and SEPIC converter. ARPN J. Eng. Appl. Sci. 2015, 10, 2914-2919.

9. Mancilla-David, F.; Riganti-Fulginei, F.; Laudani, A.; Salvini, A. A Neural Network-Based Low-Cost Solar Irradiance Sensor. IEEE Trans. Instrum. Meas. 2014, 63, 583-591. [CrossRef]

10. El Khateb, A.; Rahim, N.A.; Selvaraj, J.; Uddin, M.N. Fuzzy-Logic-Controller-Based SEPIC Converter for Maximum Power Point Tracking. IEEE Trans. Ind. Appl. 2014, 50, 2349-2358. [CrossRef]

11. Tey, K.S.; Mekhilef, S.; Seyedmahmoudian, M.; Horan, B.; Oo, A.T.; Stojcevski, A. Improved Differential Evolution-Based MPPT Algorithm Using SEPIC for PV Systems Under Partial Shading Conditions and Load Variation. IEEE Trans. Ind. Inform. 2018, 14, 4322-4333. [CrossRef]

12. Lyden, S.; Haque, M.E. A Simulated Annealing Global Maximum Power Point Tracking Approach for PV Modules Under Partial Shading Conditions. IEEE Trans. Power Electron. 2016, 31, 4171-4181. [CrossRef]

13. Obukhov, S.; Ibrahim, A.; Zaki Diab, A.A.; Al-Sumaiti, A.S.; Aboelsaud, R. Optimal Performance of Dynamic Particle Swarm Optimization Based Maximum Power Trackers for Stand-Alone PV System Under Partial Shading Conditions. IEEE Access 2020, 8, 20770-20785. [CrossRef]

14. Mohamed, A.A.; Berzoy, A.; Mohammed, O.A. Design and Hardware Implementation of FL-MPPT Control of PV Systems Based on GA and Small-Signal Analysis. IEEE Trans. Sustain. Energy 2017, 8, 279-290. [CrossRef]

15. Nugraha, D.A.; Lian, K.L. Suwarno A Novel MPPT Method Based on Cuckoo Search Algorithm and Golden Section Search Algorithm for Partially Shaded PV System. Can. J. Electr. Comput. Eng. 2019, 42, 173-182. [CrossRef]

16. Padmanaban, S.; Priyadarshi, N.; Sagar Bhaskar, M.; Holm-Nielsen, J.B.; Ramachandaramurthy, V.K.; Hossain, E. A Hybrid ANFIS-ABC Based MPPT Controller for PV System with Anti-Islanding Grid Protection: Experimental Realization. IEEE Access 2019, 7, 103377-103389. [CrossRef]

17. Kumar, N.; Singh, B.; Panigrahi, B.K. Integration of Solar PV with Low-Voltage Weak Grid System: Using Maximize-M Kalman Filter and Self-Tuned P\&O Algorithm. IEEE Trans. Ind. Electron. 2019, 66, 9013-9022.

18. Liu, J.; Li, J.; Wu, J.; Zhou, W. Global MPPT algorithm with coordinated control of PSO and INC for rooftop PV array. J. Eng. 2017, 2017, 778-782. [CrossRef]

19. Ramasamy, S.; Reddy, D.; Saravanan, S.; Chitti, B.B. Comparative Analysis of RBFN andFuzzy-SVPWM Controller Based Boost TypeVienna Rectifier for 1kW Wind EnergyConversion System. J. Green Eng. 2018, 8, 177-200. [CrossRef]

20. Reddy, K.J.; Sudhakar, N.; Saravanan, S.; Babu, B.C. High Step-Up Boost Converter with Neural Network Based MPPT Controller for a PEMFC Power Source Used in Vehicular Applications. Int. J. Emerg. Electr. Power Syst. 2018, 19. [CrossRef]

21. Yang, B.; Zhong, L.; Zhang, X.; Shu, H.; Yu, T.; Li, H.; Jiang, L.; Sun, L. Novel bio-inspired memetic salp swarm algorithm and Aapplication to MPPT for PV systems considering partial shading condition. J. Clean. Prod. 2019, 215, 1203-1222. [CrossRef]

22. Meenakshi Sundaram, B.; Manikandan, B.V.; Praveen Kumar, B.; Prince Winston, D. Combination of Novel Converter Topology and Improved MPPT Algorithm for Harnessing Maximum Power from Grid Connected Solar PV Systems. J. Electr. Eng. Technol. 2019, 14, 733-746. [CrossRef]

23. Christabel, S.C.; Srinivasan, A.; Winston, D.P.; Kumar, B.P. Reconfiguration solution for extracting maximum power in the aged solar PV systems. J. Electr. Eng. 2016, 16, 440-446. 
24. Villalva, M.G.; Gazoli, J.R.; Filho, E.R. Comprehensive Approach to Modeling and Simulation of Photovoltaic Arrays. IEEE Trans. Power Electron. 2009, 24, 1198-1208. [CrossRef]

25. Schmidt, H.; Burger, B.; Bussemas, U.; Elies, S. How fast does an MPP tracker really need to be? In Proceedings of the 24th European Photovoltaic Solar Energy Conference, Hamburg, Germany, 21-25 September 2009.

26. Ramesh, B.N.; Arulmozhivarman, P. Dynamic Neural Network Based Very Short-Term Wind Speed Forecasting. Wind Eng. 2014, 38, 121-128. [CrossRef]

27. Lin, W.-M.; Hong, C.-M.; Chen, C.-H. Neural-Network-Based MPPT Control of a Stand-Alone Hybrid Power Generation System. IEEE Trans. Power Electron. 2011, 26, 3571-3581. [CrossRef]

28. Saravanan, S.; Ramesh Babu, N. RBFN based MPPT algorithm for PV system with high step up converter. Energy Convers. Manag. 2016, 122, 239-251. [CrossRef]

29. Tiwari, R.; Krishnamurthy, K.; Neelakandan, R.; Padmanaban, S.; Wheeler, P. Neural Network Based Maximum Power Point Tracking Control with Quadratic Boost Converter for PMSG-Wind Energy Conversion System. Electronics 2018, 7, 20. [CrossRef]

30. Erickson, R.W.; Maksimovic, D. Fundamentals of Power Electronics; Springer Science \& Business Media: Boston, MA, USA, 2007. 